\title{
Numerical Modeling of the Severe Cold Weather Event over Central Europe (January 2006)
}

\author{
D. Hari Prasad, ${ }^{1}$ Joanna Wibig, ${ }^{2}$ and Marcin Rzepa ${ }^{2}$ \\ ${ }^{1}$ Centro de Geofisica (CG/UE), University of Evora, 7000 Evora, Portugal \\ ${ }^{2}$ Department of Meteorology and Climatology, University of Lodz, 90-131 Lodz, Poland \\ Correspondence should be addressed to D. Hari Prasad, dasarihariprasad@rediffmail.com
}

Received 23 January 2010; Revised 26 April 2010; Accepted 15 June 2010

Academic Editor: Zhaoxia Pu

Copyright ( 2010 D. Hari Prasad et al. This is an open access article distributed under the Creative Commons Attribution License, which permits unrestricted use, distribution, and reproduction in any medium, provided the original work is properly cited.

\begin{abstract}
Cold waves commonly occur in higher latitudes under prevailing high pressure systems especially during winter season which cause serious economical loss and cold related death. Accurate prediction of such severe weather events is important for decision making by administrators and for mitigation planning. An Advanced high resolution Weather Research and Forecasting mesoscale model is used to simulate a severe cold wave event occurred during January 2006 over Europe. The model is integrated for 31 days starting from 00UTC of 1 January 2006 with $30 \mathrm{~km}$ horizontal resolution. Comparison of the model derived area averaged daily mean temperatures at $2 \mathrm{~m}$ height from different zones over the central Europe with observations indicates that the model is able to simulate the occurrence of the cold wave with the observed time lag of 1 to 3 days but with lesser intensity. The temperature, winds, surface pressure and the geopential heights at $500 \mathrm{hPa}$ reveal that the cold wave development associates with the southward progression of a high pressure system and cold air advection. The results have good agreement with the analysis fields indicates that the model has the ability to reproduce the time evolution of the cold wave event.
\end{abstract}

\section{Introduction}

Advance information of extreme weather phenomena such as cold waves is very important to avert their adverse impact on the life and economy of a given region. Prediction of the cold weather events in advance of 15 to 30 days is a challenging issue for the researchers and is useful for the administrators to minimize the damage and for adopting necessary mitigation measures. Cold waves belong to the weather phenomenon which occurs when marked cooling of the air persists for a period of at least few days [1, 2]. Cold waves generally occur with an advection of cold air mass over a large area associated with radiative cooling when a blocking anticyclone develops and persists for at least few days.

Several studies have reported observed strong warming in the end of the nineteen century, with an evident increase in minimum and maximum temperatures in Central and Eastern Europe [3,4] and in the whole Baltic region [5] indicating that mortality risk increases every winter in Central and Eastern Europe [6]. Though the rise in mean daily and mean minimum temperatures does not necessarily affect the frequency of extreme cold weather [7]; however it exerts a strong impact on the environment and society.

Numerical simulation of cold waves requires incorporation of the various atmospheric processes in the model such as the interaction of the large-scale atmospheric flow with the local-scale circulation, interaction of the surface and planetary boundary layer (PBL) with the free atmosphere and vice versa, and radiation transfer. In numerical models the subgrid scale processes are parameterized to define their interaction with grid-resolvable prognostic variables. The application of recently developed high resolution atmospheric models like the Advanced Research Weather Forecasting Model (ARW) is expected to improve the prediction of extreme weather events as the regional models are based on more advanced dynamical and physical processes. However, an important aspect of high resolution models is their spin-up time. When operated in climate mode they require simulation lengths exceeding the spinup time which is of the order of several days [10-16] for 
TABLE 1: Details of the ARW model.

\begin{tabular}{ll}
\hline Model Name & NCEP/NCAR ARW \\
\hline Model type & Primitive equation, Non- hydrostatic \\
& 28 sigma levels 1.000, 0.990, 0.978, 0.964, 0.946, 0.922, 0.894, 0.860, 0.817, 0.766, \\
Vertical resolution & $0.707,0.644,0.576,0.507,0.444,0.380,0.324,0.273,0.228,0.188,0.152,0.121$, \\
& $0.093,0.069,0.048,0.029,0.014,0.000$ \\
Horizontal resolution & $30 \mathrm{~km}$ \\
Time step & 180 Seconds \\
Domain of integration & $6.7624 \mathrm{E}-37.2992 \mathrm{E} ; 42.605 \mathrm{~N}-61.1074 \mathrm{~N}$ \\
Short wave radiation scheme & Dudhia scheme \\
Long wave radiation scheme & Rapid Radiative Transfer Model for long wave radiation \\
Surface scheme & 5 -layer thermal diffusion scheme \\
Convection scheme & Kain- Fritsch (KF) [8, 9]. \\
PBL scheme & YSU scheme \\
Explicit moisture scheme & WSM 3-class Simple Ice \\
Initial and boundary conditions & NCEP reanalysis data available at 2.5 degree and boundary conditions are updated \\
\hline
\end{tabular}

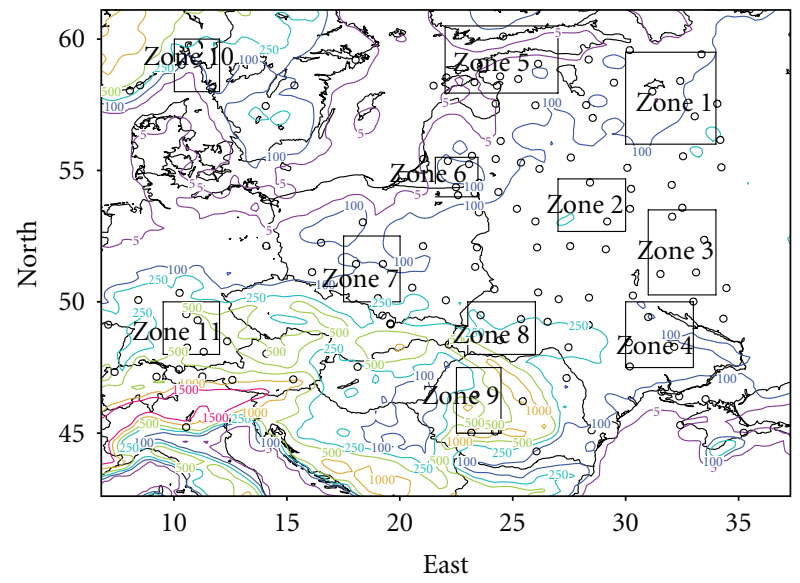

Figure 1: Model chosen domain along with the topography. The circles indicate the available station observation over the domain during 1-31 January 2006. The boxes indicate different zones chosen for analysis.

the atmospheric component, and even much longer for the surface component. A typical threshold length for a climate mode run using regional models is 1 month $[11,17]$.

Weather and climate forecasting is usually done following statistical, synoptic, and numerical techniques. The statistical methods depend on the interrelationships between observable atmospheric variables and their influence on the climatic behavior. Though statistical methods provide certain broad trends of weather and climate systems, they find limited use as the climate system is highly nonlinear and simple correlations between any two variables may not always provide estimate of any variable especially over long periods like seasons. The synoptic methods bank upon systematic analysis of large-scale trends of the dynamical systems based on a series of observation charts called the synoptic charts. However this method is subject to the skill of the interpreter and cannot be applied for time periods beyond a few days due to the inherent variability of the atmospheric system. Atmospheric dynamical models are based on the physical and dynamical processes of the atmosphere and hence provide the basis for objective predictions of the ever-changing atmospheric conditions quantitatively; however their success depends on the accuracy of the initial and boundary conditions and the appropriateness of the physics used in the model. Atmospheric General Circulation models (AGCMs) are used to simulate the trends in climate patterns over the global. The GCM simulations provide the information on the movement of the large scale pressure systems, air masses, and associated climate over various parts of the globe. However, the GCMs have a limitation of predicting the regional characteristics due to coarse resolution. The GCMs find a limited application when it comes to the disaster mitigation and decision making aspects where much finer quantitative predictions along with precise time of occurrence of a weather event is the necessary key information required by the administrators. The availability of regional models with horizontal resolutions of $30-50 \mathrm{~km}$ permits simulating the fine scale seasonal weather patterns to study the regional climatic characteristics more precisely. The theoretical limit for the useful daily weather forecast is about 10-14 days, but in practical application, the current limit is about 5-7 days. For longer periods of about months or seasons average temperature and precipitation can only be assessed; however the skill of such forecasts is low. The developments of numerical models provide the basis for an improved understanding of monthly and seasonal weather variation and for an enhanced ability to predict them with reasonable skill. Even a small improvement in the skill of extended range forecasting of extreme weather events may be helpful to take necessary precautions and to minimize weather-related losses or deaths and is important for substantial economic benefit.

In this study the objective is to examine the WRF ARW model capability for extended range seasonal prediction by simulating the extreme cold weather event that occurred 
00UTC of 1 January 2006

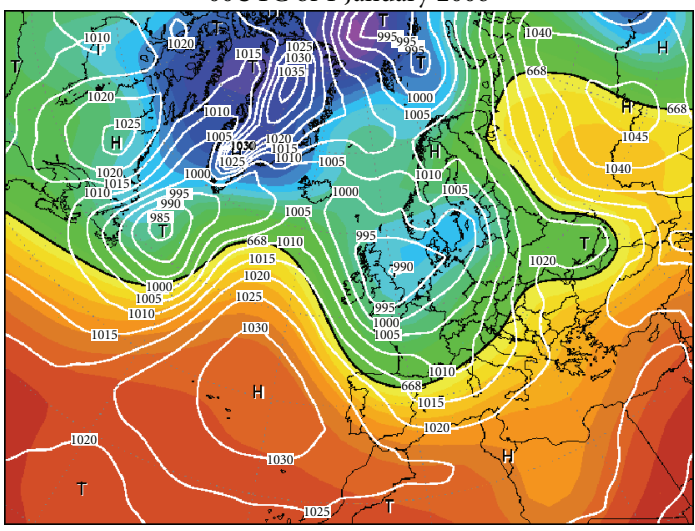

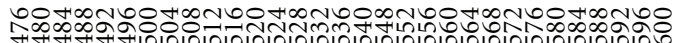

(a)

00UTC of 10 January 2006

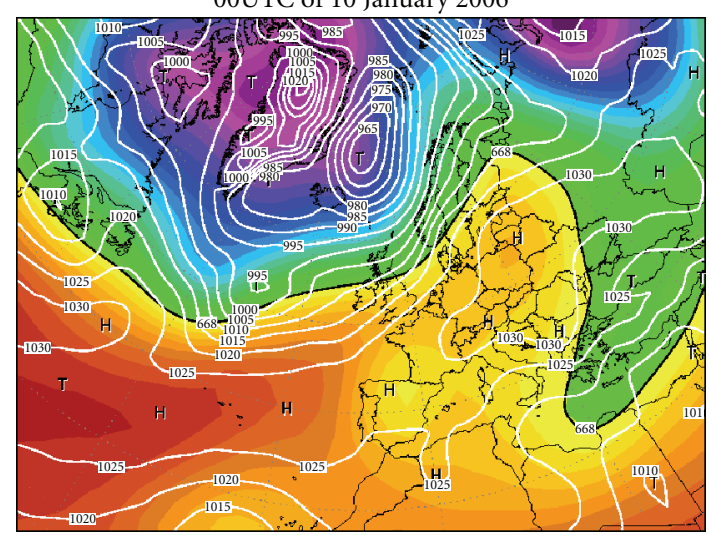

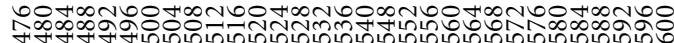

(c)

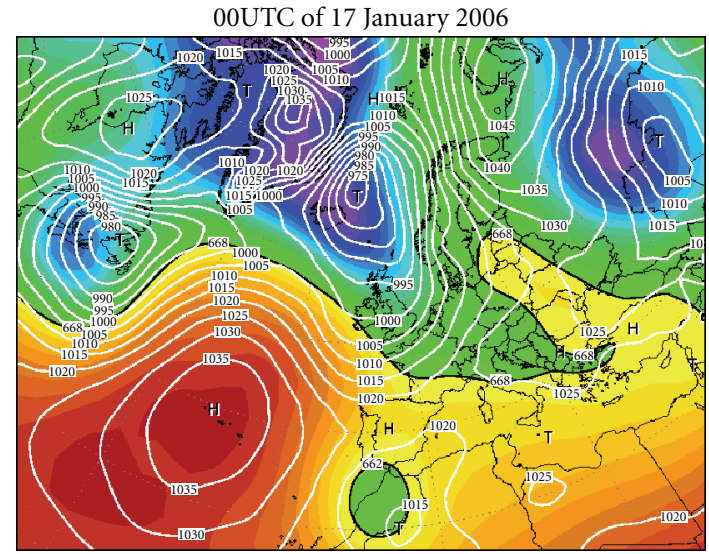

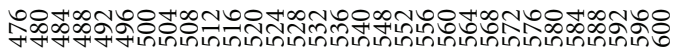

(e)
00UTC of 5 January 2006

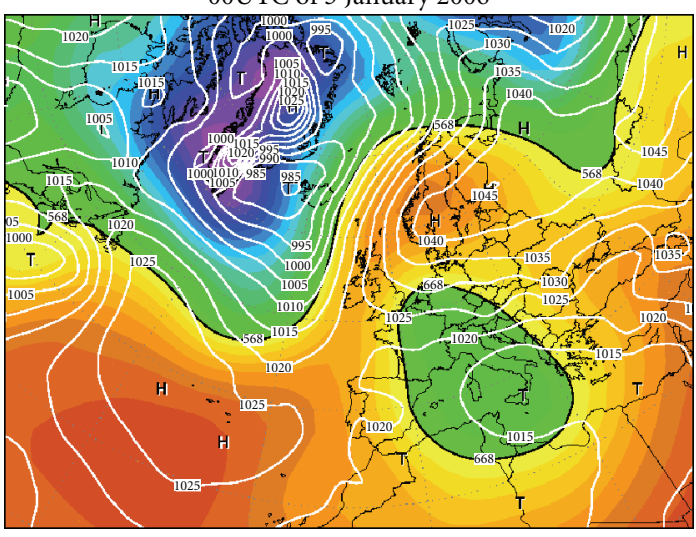

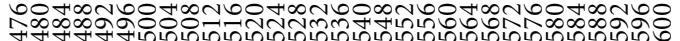

(b)

00UTC of 15 January 2006

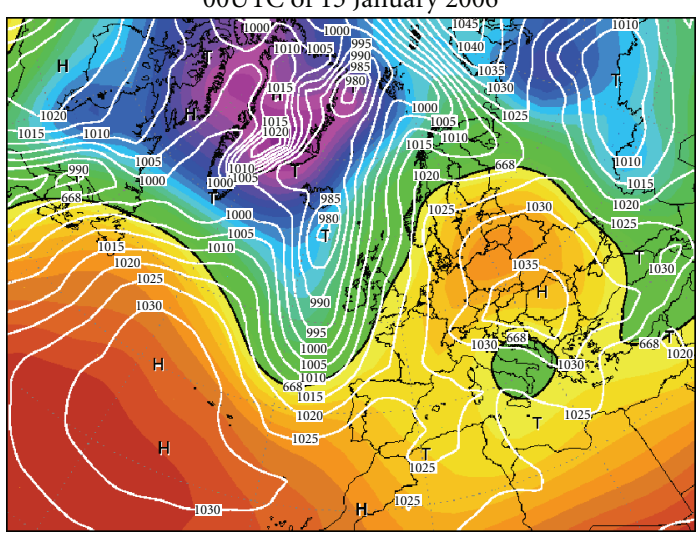

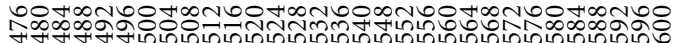

(d)

00UTC of 18 January 2006

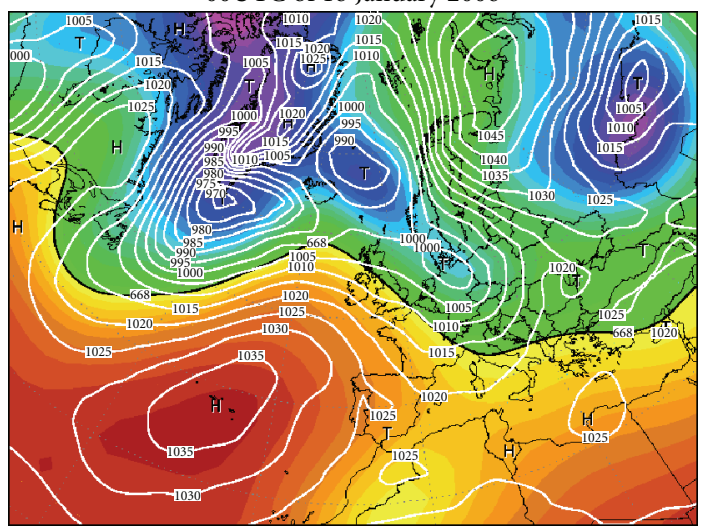

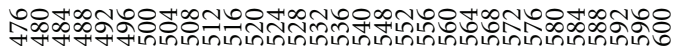

(f)

FIgURE 2: Continued. 
00UTC of 20 January 2006

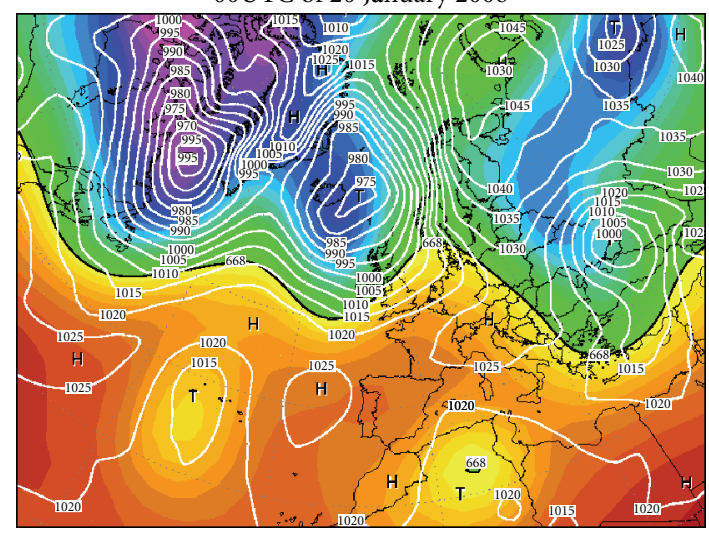

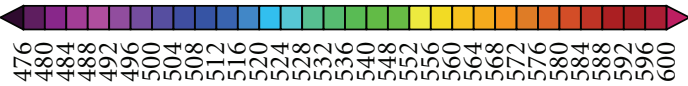

(g)

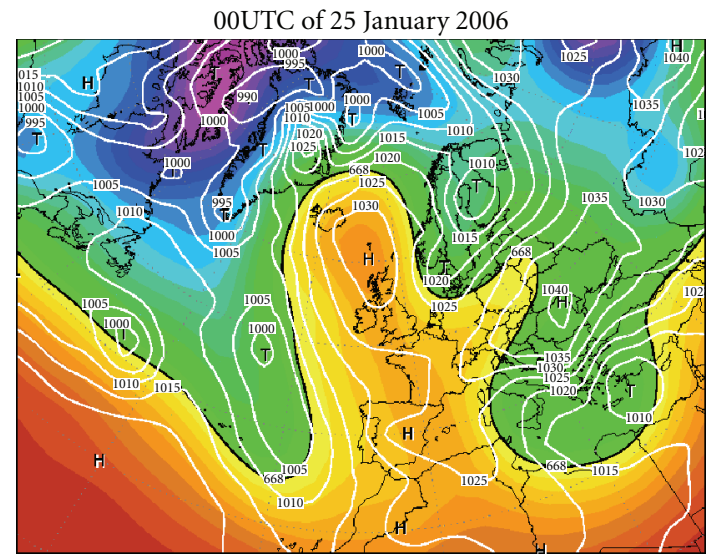

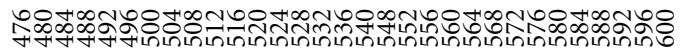

(i)
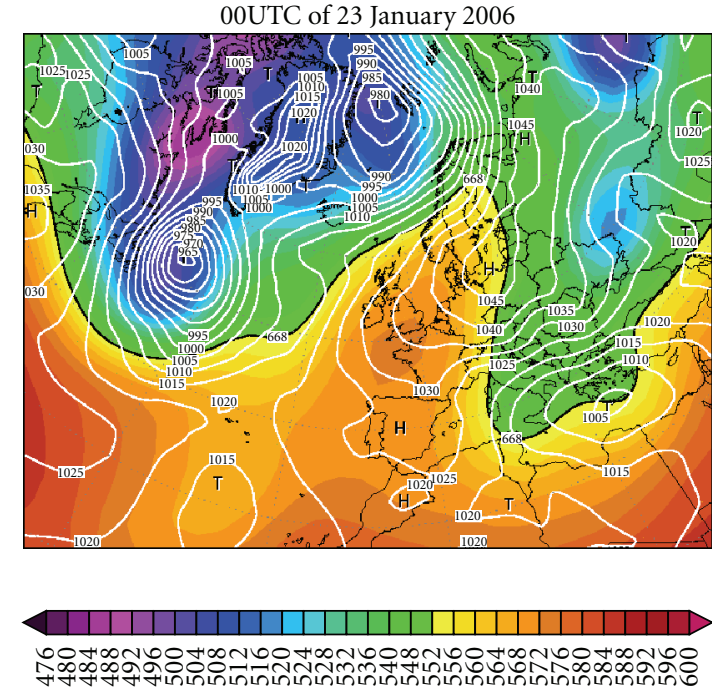

(h)

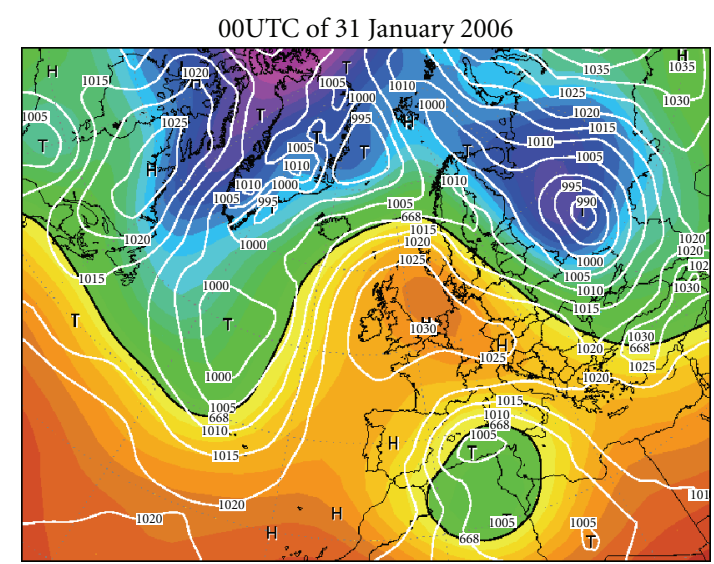

\begin{tabular}{l}
\hline \\
\hline
\end{tabular}

(j)

Figure 2: Geopotential height (shaded) at $500 \mathrm{hPa}$ level (gpdm) and mean seal level pressure (contours) during the period 1-31 January 2006 from NCEP 2.5 degree reanalysis data.

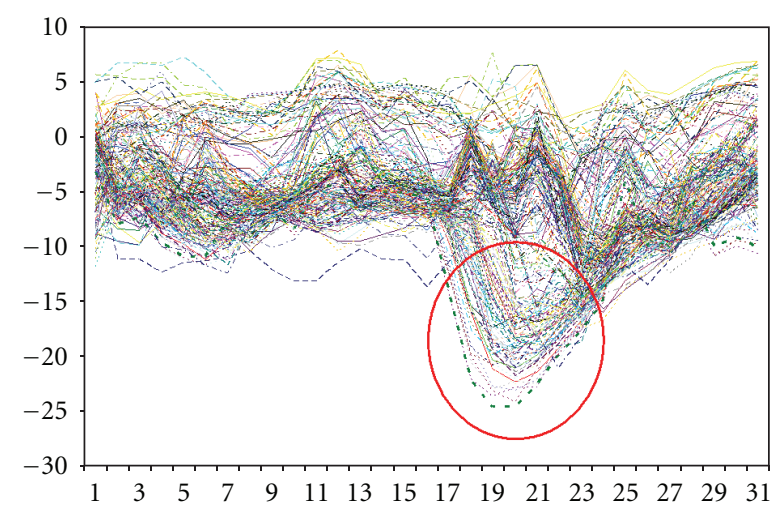

(a)

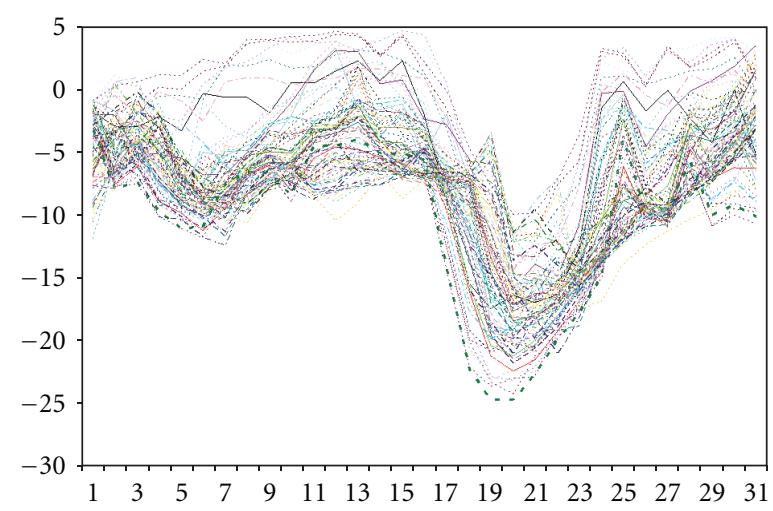

(b)

Figure 3: (a) The time series of the temperature at $2 \mathrm{~m} \mathrm{(C)}$ at different grid points located over model domain. (b) The time series of the temperatures at different grid points with the fall in temperatures less than $-20^{\circ} \mathrm{C}$ during one-month period separated from Figure $3(\mathrm{a})$. 
over Central Europe during January 2006 with the WRF model. The model-derived intensity and development of the cold wave analyzed by comparing temperature at $2 \mathrm{~m}$ height, surface pressure, low level wind flow, and geopotential height at $500 \mathrm{hPa}$. The paper is organized as follows. A brief description of the cold wave in Central Europe is given is Section 2, the details of the model configuration and initialization are presented in Section 3, the results of the simulations are discussed in Section 5, and the summary and conclusions are presented in Section 6. Finally, the applicability of this study is discussed in Section 7.

\section{Description of Cold Wave during January 2006}

Cold waves at higher latitudes belong to the class of extreme weather conditions during winter. The observations show a severe cold wave occurred in January 2006 in Central Europe. This winter was extremely cold with snowy conditions observed over a vast area of Central, Eastern, and Southern Europe and relatively mild winter observed in Northern Norway. The phenomenon started in the European part of Russia, where a severe cold wave occurred between January $17-18$ with a temperature drop up to about $-30^{\circ} \mathrm{C}$ in Moscow, the coldest situation ever since the winter of 1978-1979. On 20 January 2006 temperatures lower than $-40^{\circ} \mathrm{C}$ occurred in European Russia where the lowest temperature on record was about $-42.1^{\circ} \mathrm{C}$ in 1940 . The cold wave extended to Central European parts of Poland, Slovakia, and Austria with the recorded low temperatures below $-30^{\circ} \mathrm{C}$, and snow and cold weather penetrated to the south in Eastern Europe with heavy snowfalls over Acropolis in Athens, Greece on the 25th of January. The abnormal conditions gradually abated towards the end of the month, when temperatures dropped to $-38^{\circ} \mathrm{C}$. There were numerous cold-related deaths reported, primarily in Russia (50 people), Ukraine (181), Romania (27), Poland (25), Czech Republic (10), and Bulgaria (3) (Reuters). Heavy snowfalls were attributed for an avalanche near Dushanbe in Tajikistan. The cold weather in Southern Central and Eastern Europe has spread from Italy to the Urals. As January 2006 is one of the reported extreme cold weather over European region, this event is taken as a case study to simulate and also to understand the probable causes for its occurrence.

The synoptic situation of the cold wave during 1-31 January 2006 is depicted in Figure 2 using NCEP reanalysis data for surface pressure and geopotential at $500 \mathrm{hPa}$ level. The analysis shows that at 00UTC of 1 January 2006, a low-pressure system is located over Central Europe. The trough is elongated from the head of the Baltic Sea to the south. The thickness of the atmospheric layer (i.e., geopotential difference) from surface to $500 \mathrm{hPa}$ is seen to increase from Northern Europe to Southern Europe. After five days, that is, at 00UTC of 5 January, the whole region is completely replaced with high pressure system, and the low pressure is limited to a small region over east of Iceland. Over that region thickness of the geopotential is high and moved toward south of the region and with encircled lower thickness of geopotential observed over Central Europe and neighbor hood. The thickness of the geopotential increased over entire region, and it last up to 14 January with minor day-by day variations. The synoptic flow pattern was more or less constant during this whole period. At 00UTC of 15 January the weather map show well-defined low pressure systems observed over south of Iceland, north-eastern parts of Green land, and north-eastern parts of Central Europe. A well-defined high-pressure system with high geopotential thickness is located over Central Europe. A well-defined trough region is observed at west of Central Europe and also over North eastern parts of the Central Europe. From this day onwards the thickness of the height contours slowly started decreasing over Central Europe, and after two days the weather map showed that the axis of the trough is extended from the East of the Iceland to Central Europe also another trough region developed from north-eastern parts of Central Europe. Well-defined low-and-high pressure systems are observed, and the southward progress of the cold wave is observed. This type of weather pattern is almost observed up to 18 January. After this day onwards the low pressure system moved towards Iceland, and high pressure system started moving towards the Central Europe and was sustained up to 26 January and then it started moves towards west and then north. This narrow zone of high pressure system is associated with low pressure systems in both east and west. During this period another branch of cold wave also slowly developed and started progressing from North east of the Central Europe towards Europe and that was sustained up to 26 January and then slowly disappeared.

\section{Model Configuration and Initialization}

A nonhydrostatic primitive equation ARW model developed by the National Center for Atmospheric Research (NCAR) was used in the present study. The ARW is a flexible stateof-the-art mesoscale atmospheric simulation system that is portable and efficient on a range of parallel computing platforms $[18,19]$. The model has higher-order numerics and mass conservation characteristics [20]. For the present study the model was designed with a single domain of $30 \mathrm{~km}$ horizontal resolution. As the extratropical weather systems are relatively slow moving systems and large in size, the domain area was chosen to be about $3000 \times 3000 \mathrm{sq} \cdot \mathrm{km}$ (6.7624E-37.2992E; 42.605N-61.1074N) which covers most of Central European and adjacent regions (Figure 1). The model physics used for the simulation included Kain-Firstch scheme for convection, Rapid Radiative Transfer Model for long wave radiation, Yonsei University scheme for planetary boundary layer turbulence, and the WSM 3-class Simple Ice scheme for explicit moisture processes (Table 1). The model was integrated for 31 days starting from 00 UTC of 1 January, 2006 to study the movement of the cold wave front.

Our first objective was to test whether the 31-day model simulations provide reasonable agreement with observations on this timescale, so that a strategy for real-time forecasts could be devised later using the larger-scale model forecasts like GFS or other global models that provide seasonal 


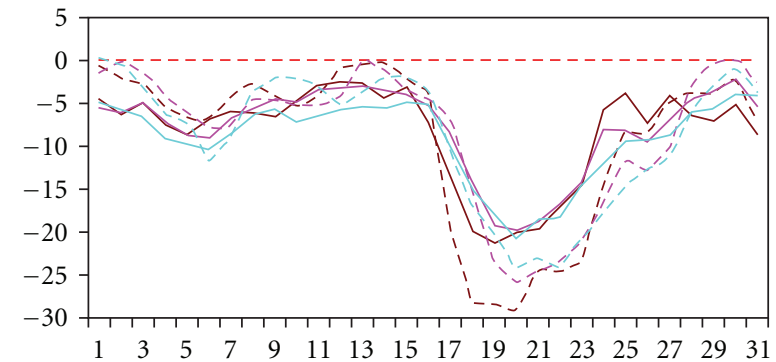

- Zone 1
$-\quad$ Zone 2
Zone 3

- - Observation 1

- - - Observation 2

Observation 3

(a)

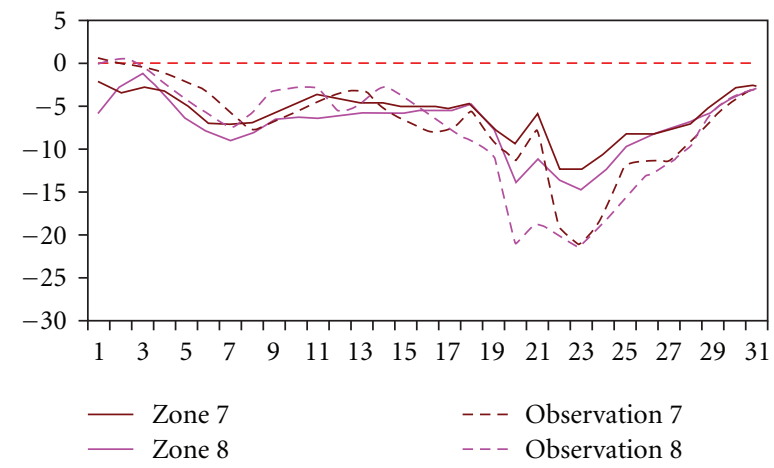

(c)

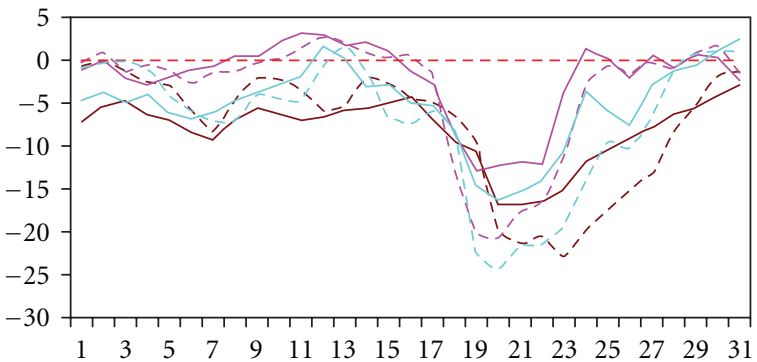

- Zone 4
- Zone 5
- Zone 6

- - - Observation 4

- - - Observation 5

- - Observation 6

(b)

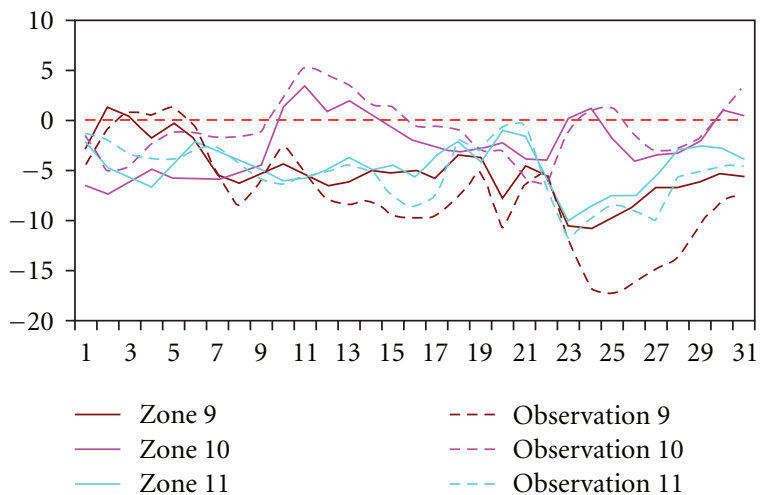

(d)

Figure 4: Time series of the daily mean area averaged temperature (C) at $2 \mathrm{~m}$ height for different zones along with the averaged station daily mean surface temperature for corresponding zone.

forecasts. Hence in the present study, the initial conditions for the model were given from NCEP reanalysis data [21] available at $2.5 \times 2.5$ degree resolution corresponding to 00 UTC 1 Jan 2006. The terrain, land cover, and soil types data over the region of study are obtained from the USGS topography data with a resolution of 10 minutes (roughly $18 \mathrm{~km}$ ). The time-varying lateral boundary conditions are provided at every 6 hours interval during the entire period from NCEP reanalysis data.

\section{Observational Data}

The daily mean temperatures from 106 meteorological stations collected from different parts of Europe for the period 1-31 January 2006 were used for comparison. Out of 106 stations 85 records were taken from European Climate Assessment and Dataset [22], and 21 Polish records were taken from Institute of Meteorology and Water Management.

The intensity of the simulated cold wave was studied on the basis of a comparison of the observed surface temperatures with the model results. The movement of the pressure systems which caused the cold wave during that period was discussed from model fields for surface pressure and $500 \mathrm{hPa}$ geopotential height. The above fields from WRF model were compared with the high-resolution NCEP
Final analysis (FNL) data available at 1 degree horizontal resolution to assess the skill of the model in capturing the time and intensity of the cold weather event.

\section{Results and Discussions}

Unlike global models, numerical simulations using limited area models require specification of atmospheric variables at the lateral boundaries at regular time intervals to represent the time-varying large scale weather condition across the boundaries of the domain and to permit the outside flow in to the model domain. The specification of time varying lateral boundary conditions will also influence the model atmosphere evolution, which is due to the model dynamics. The mesoscale model ARW described in the previous section provides the option to use either a single domain or nested multiple domains with one-way or two-way interaction. The general practice is to use as much as possible higher resolution which is constrained by computational resources. For this study, the simulation was conducted to examine the performance of the model on the prediction of the cold wave passage over Central Europe region with a single domain of $30 \mathrm{~km}$ resolution and updating the lateral boundary conditions once every 6 hours to represent the change in the outer atmospheric condition at that interval. The model 


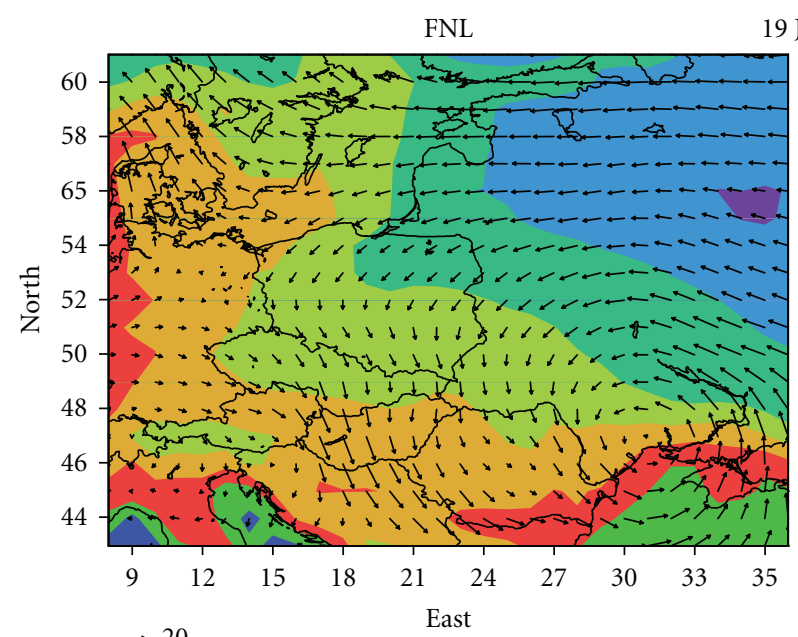

19 January 2006

Model
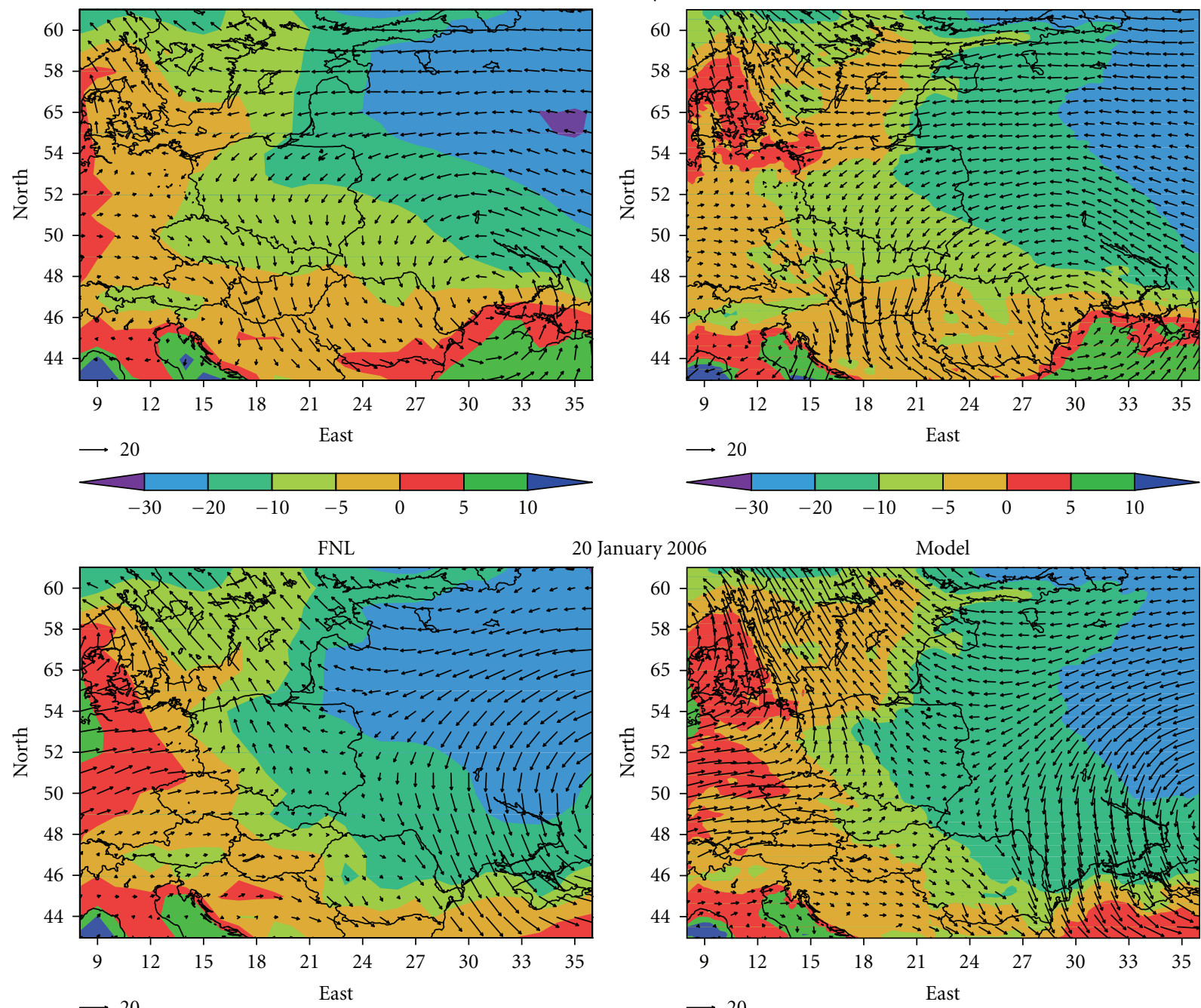

20 January 2006

Model

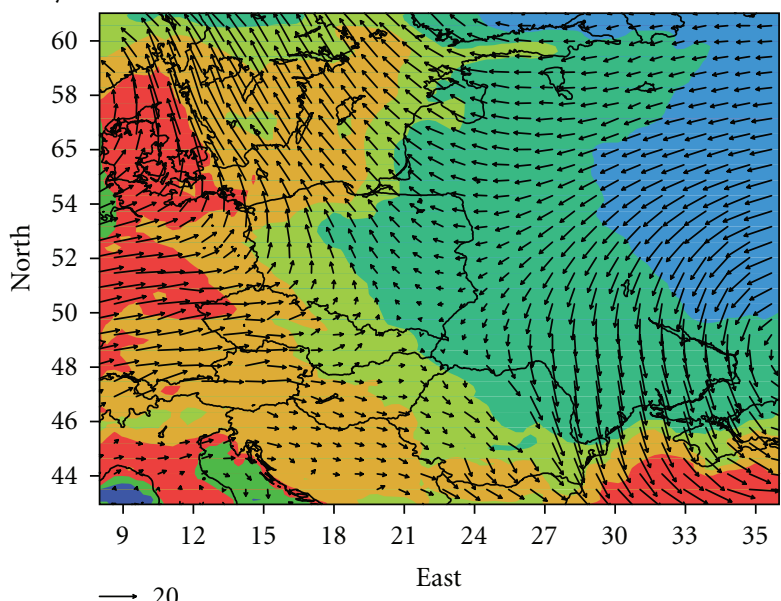

$\longrightarrow 20$

$\longrightarrow 20$
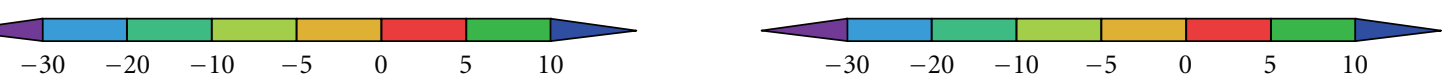

21 January 2006
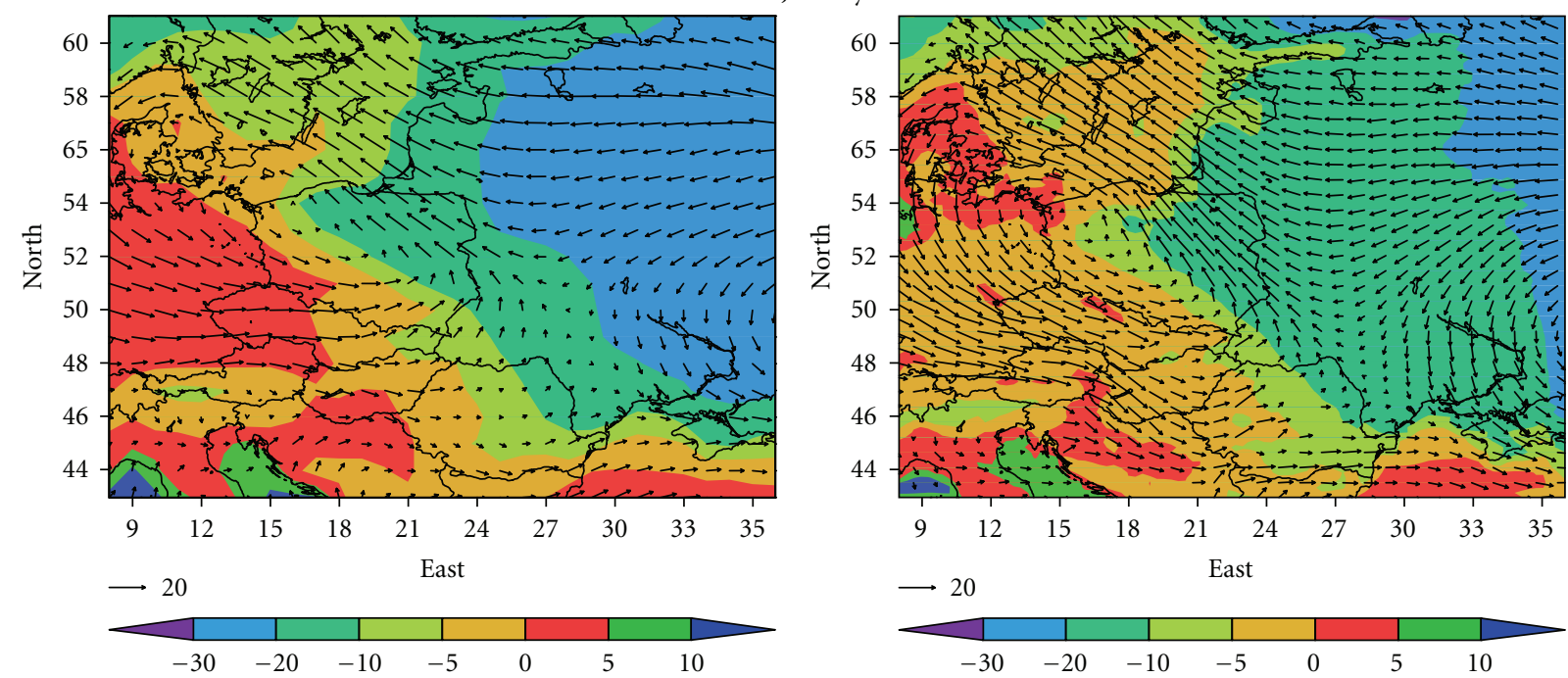

FIgUre 5: Continued. 


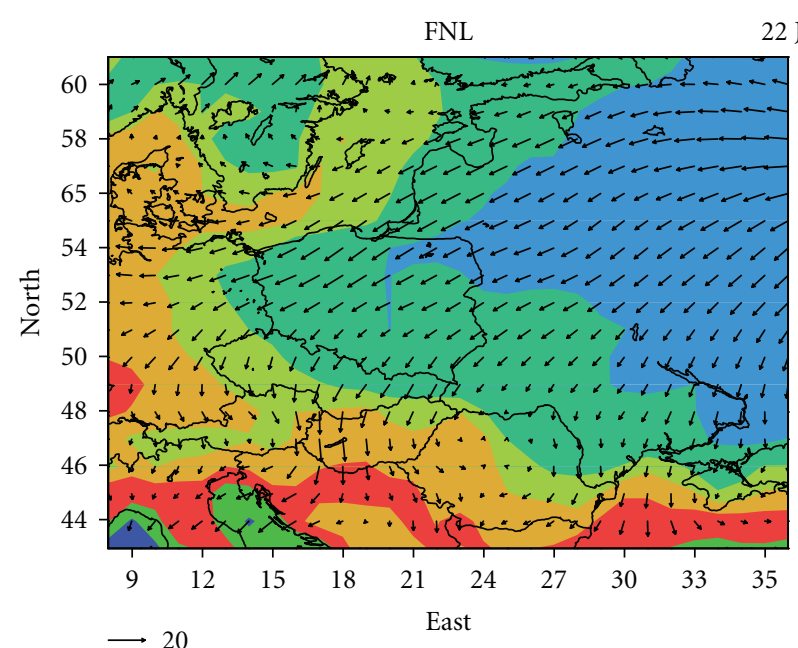

22 January 2006

Model

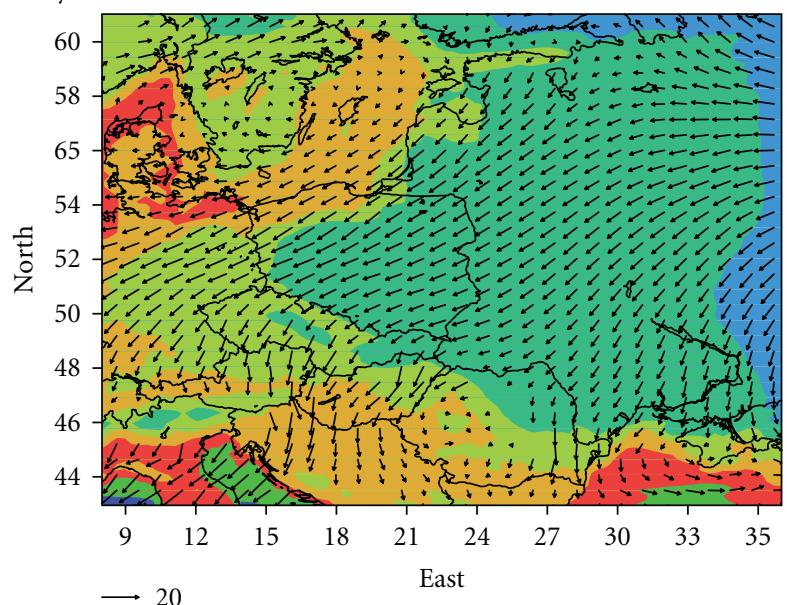

$\longrightarrow 20$

$\longrightarrow 20$

East
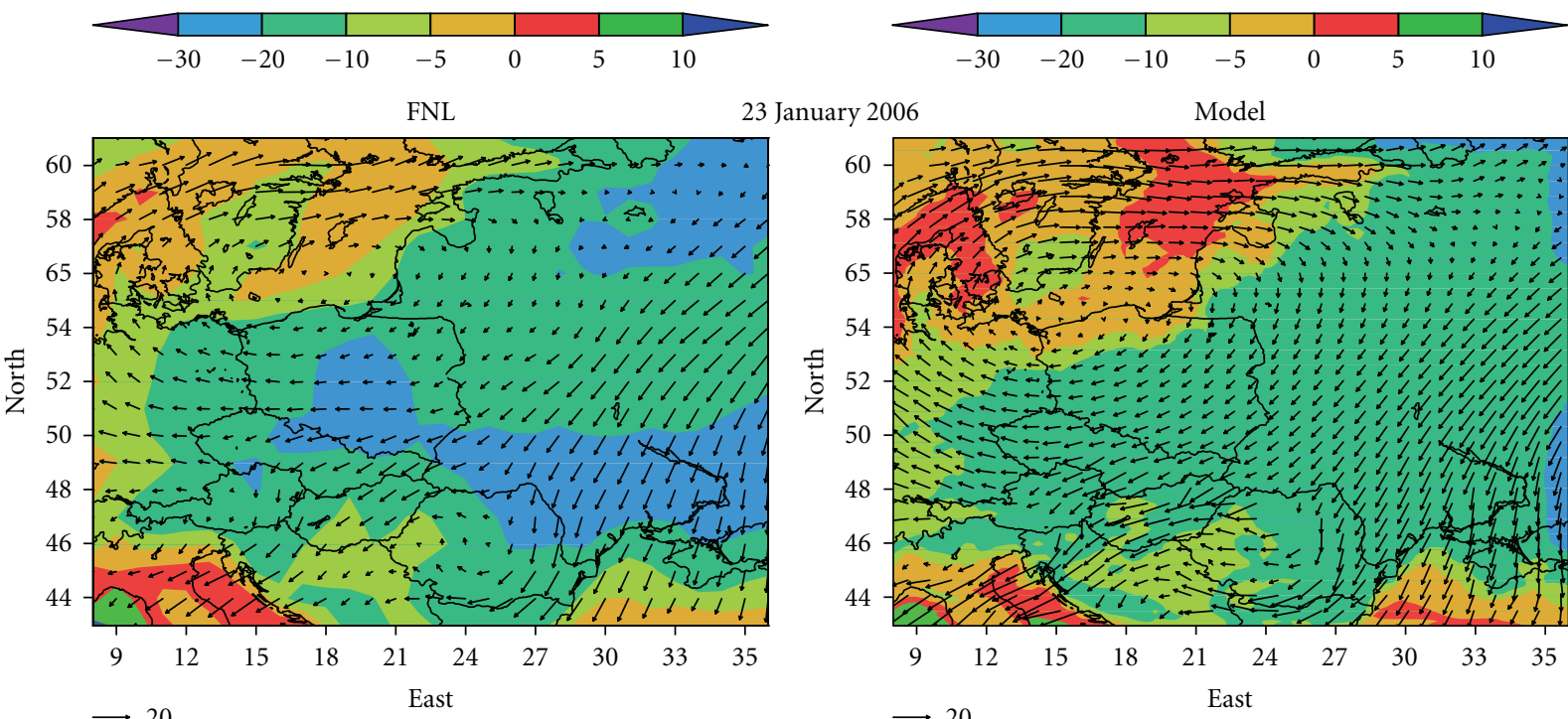

23 January 2006

Model
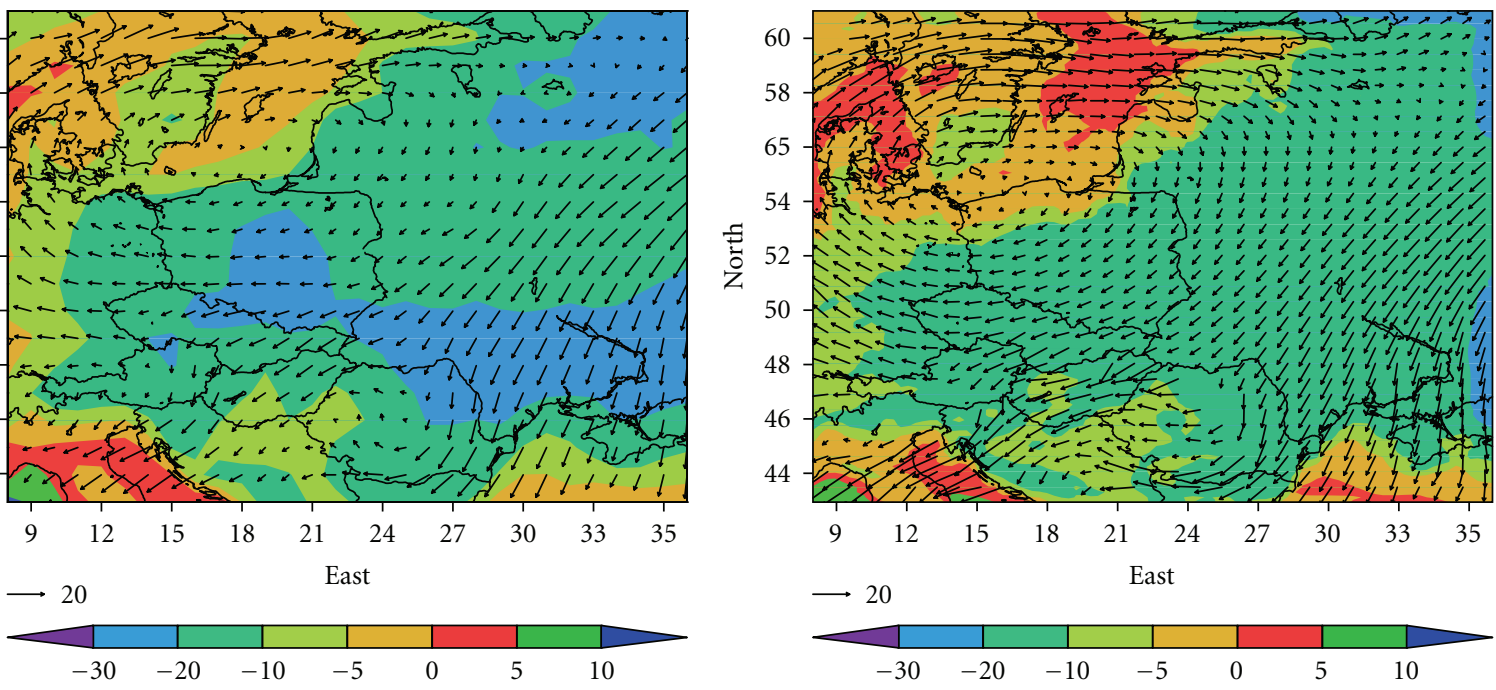

FIGURE 5: Daily mean temperature (C) at $2 \mathrm{~m}$ (shaded) along with winds at $925 \mathrm{hPa}$ for FNL (left panel) and ARW model (right panel) at different times.

evolution of cold wave, in terms of intensity and movement, was analyzed and discussed by a comparison with the available observations. The model predicted intensification of cold wave during the period 1 to 31 January 2006 was analyzed in terms of the model-simulated daily averaged air temperature at $2 \mathrm{~m}$ height and the comparison with corresponding observations.

As the first step, the variations of model-derived daily mean temperatures at $2 \mathrm{~m}$ above ground level (AGL) were analysed over the entire domain, and a set of zones are identified based on the differences in the topography. Figure 3(a) shows the daily mean temperatures at $2 \mathrm{~m}$ AGL for different grid points during entire January. It shows a fall of about $-10^{\circ} \mathrm{C}$ (sometimes even below $-20^{\circ} \mathrm{C}$ ) in daily mean temperatures for a period of 2 to 5 days at some grid points. This trend is not found uniformly at all grid points indicating that the simulated temperature fields drastically varied at regional scale. The variation in the temperature field is probably due to the variations in elevation, land use category, and so forth in different parts of the modeling domain. Figure 3(b) shows the time series of temperature for those grid points at which temperature had fallen below $-10^{\circ} \mathrm{C}$. From these two pictures, it is understandable that the model is able to predict the cold wave scenario over some area and not over the entire domain. This was analyzed by observational comparison further. Based on results from Figures 3(a) and 3(b) a few areas were identified and categorized as zones. Accordingly zone 1 to zone 8 represent areas with mean daily temperatures below $-10^{\circ} \mathrm{C}$ for few days (boxes in Figure 1) and zone 9, 10, and 11 correspond to areas where the fall in temperature is not below $-10^{\circ} \mathrm{C}$. Out of all these 11 zones, the zones from 1 to 8 have elevations less 
than $150 \mathrm{~m}$, and the other three zones have relatively higher elevation. Zone 5 has both ocean and land and represents coastal region. Zone 10 is a coastal region and also has higher elevation. The area averaged temperatures for the above zones for each day in January 2006 were compared with the observed daily mean surface temperature for the stations (shown circles in Figure 1) located within and very close to the selected zones. The model diagnostic statistics of area averaged temperature were computed between ARW-derived daily mean temperatures and the observations (correlation, standard deviation, bias, RMSE) and presented in Table 2. It is observed that in all zones the simulated temperature correlated well with observations in the range of 0.765 to 0.953 with a negative bias for zones 3,4 , and 10 and with positive bias for the remaining zones. The results indicate the model showed positive and negative bias over different zones. A strong positive bias (2.4651) is observed at zone 9 which is a mountain region with correlation coefficient of 0.8835 . The next positive bias maxima of 1.79 are found for zone 6 located close to coast with correlation of 0.898 followed by zone 5 (land and ocean) with a bias of 1.3872 and with highest correlation of 0.95 . This indicates that the simulated air temperature has strong positive bias over mountain and coastal regions. A strong negative bias $(-1.621)$ and low correlation (0.7659) are observed over zone 10 which is a coastal and mountainous area. Thus the ARW has reasonably simulated temperature at all zones except the mountainous and coastal regions. Positive correlations above 0.76 at all zones and at 95\% significance indicate ARW model skill for quantitative temperature simulations.

5.1. Model-Derived Temperatures at $2 \mathrm{~m}$ Height. The time series of the area averaged daily mean temperatures at 2 meter height from zones 1, 2, and 3 located in the eastern parts of the domain are presented in Figure 4(a) along with the station averaged daily mean surface temperatures. Results clearly show that the model is able to pick up the day-to-day variation of temperature over the eastern parts of the domain but with a slight underestimation during the intense cold wave period. The difference between the model and observations is not much at the onset of the cold wave conditions but very significant during the intense cold wave period. The difference in model temperature and observations is about $3-5^{\circ} \mathrm{C}$ in the onset phase and about $10^{\circ} \mathrm{C}$ during the peak cold wave period. The variation of simulated temperature in January 2006 is well matched with the observations is a correlation coefficient of 0.944 and with positive bias of 0.81 in zone 1 where the cold wave appeared around 17 January, intensified, and sustained for 2 to 3 days by 19 January and gradually disappeared thereafter. A similar situation was also observed over zone 2 with correlation coefficient 0.940 (bias of 0.495 ) but with a lag of one day and over zone 3 (with correlation coefficient 0.953 and a negative bias of -0.204 ) and with a lag of 2 days. Similarly over zone 4 (the southeastern parts of the domain) the model values matched well with the averaged station observations with a correlation of 0.900 (Figure 4(b)), but model temperatures were slightly underestimated with a negative bias of -0.236 .
The decrease in temperature started from 19 of January, attained minimum value by 21 January and the very cold weather situation sustained up to the 24 of January. It is evident that the model well simulated the passage of the cold wave from zone 1 (from north east) to zone 4 (to the south east) closely following the observations. The mean daily temperature plots for zone 5 and 6 indicate that the cold conditions are simulated by the model from 18 to 23 of January. The temperature in zone 5 was slightly higher than that in zone 6 , which is expected as part of zone 5 covers the ocean and land parts. The correlation coefficient between the modeled and observed temperature for zones 5 and 6 was 0.950 and 0.899 with a positive bias of 1.3871 and 1.79, respectively. From Figures 4(a) and 4(b) it is noted clearly that the time difference in the drop of temperature is about 1 to 2 days. This delay in the temperature drop at different zones is due to the slow movement of the cold wave from the northeastern part (Zone 1, 2, and 3) of the domain towards the central parts (Zone 6). The extreme cold condition was sustained for three to four days causing very cold temperatures in these areas.

The model-derived area averaged $2 \mathrm{~m}$ daily mean temperature over zone 7 (central part of domain) is noted to agree well with the observations up to 21 January thereafter the model indicated overestimation of temperature (Figure 4(c)), with a correlation of 0.930 and bias of 1.16 . The model-predicted minimum temperature was evidently higher than the observed one; however the trends were reproduced reasonably well. The model simulated a fall in temperature and persistence of cold conditions for 2-3 days in the southern parts of the domain, that is, zone 8 with correlation of 0.9 reasonably agreeing well with observations but with an underestimation of low temperature by $7^{\circ} \mathrm{C}$.

The zones 9 and 11 are located in mountainous area. The time series of temperature from these zones shows that the time of occurrence minimum temperature (drop) is well simulated. However a strong positive bias of 2.465 is noted for zone 9, where the lowest temperatures were evidently higher than the observed ones (Figure $4(\mathrm{~d})$ ). The model temperature evolution in these zones may have been influenced by the land surface processes as represented by the model topography, land cover, and soil conditions which need to be examined further. Also the physical parameterizations used for the treatment of the surface energy and boundary layer turbulence need to be investigated for their application over these mountainous regions. The correlation between the simulated and observed temperatures is 0.884 and 0.783 for zones 9 and 11. The simulated temperature over the northwestern parts (zone 10) showed relatively higher daily mean temperatures than all other zones. This area is situated close to the mountains and to the Atlantic Ocean (Figure $4(\mathrm{~d})$ ). For this zone the model simulated temperature evolution of the area averaged daily mean temperature at $2 \mathrm{~m}$ height was in good agreement with the averaged daily mean station observations with a correlation of 0.766 , which is slightly lower than the correlation of all the other zones and with a strong negative bias of -1.621 .

From the above analysis of mean daily temperature evolution it is evident that the model is able to simulate the 
FNL

19 January 2006

Model
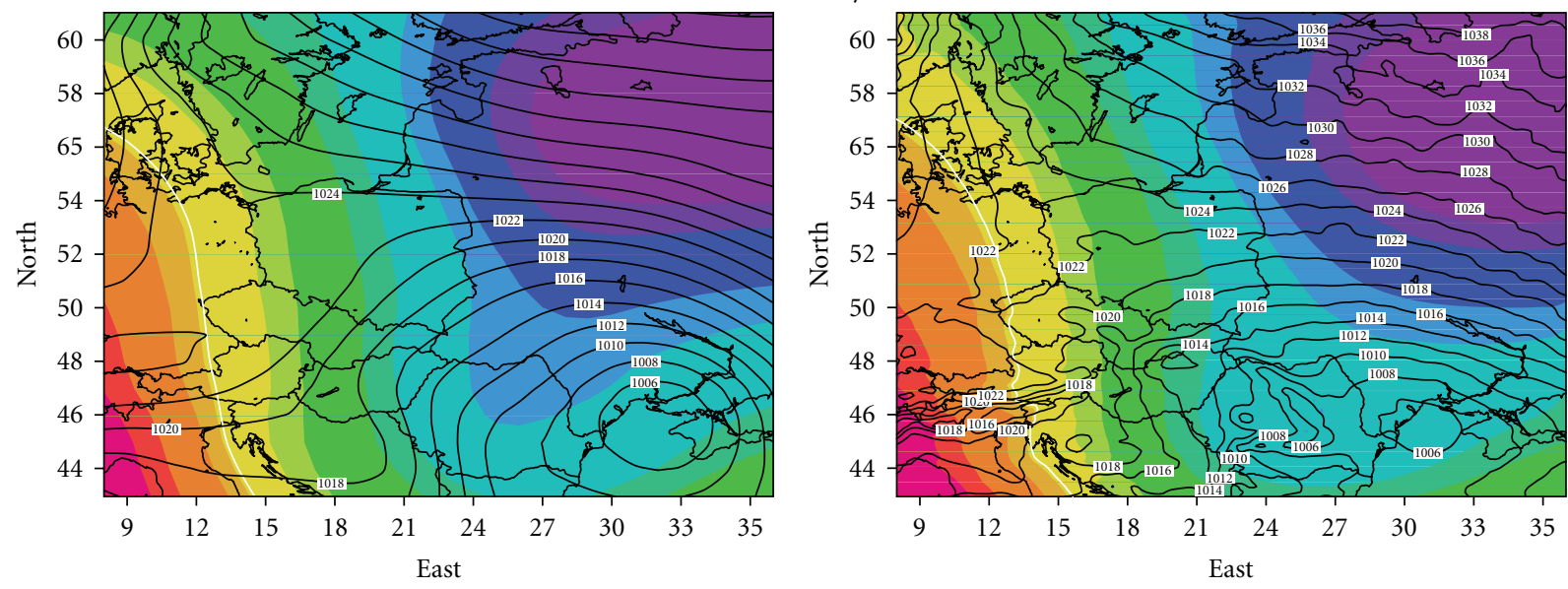

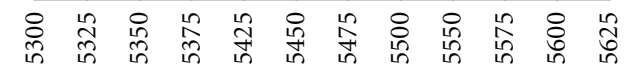
FNL

20 January 2006

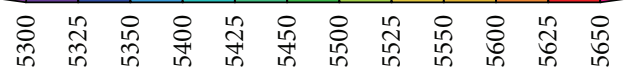
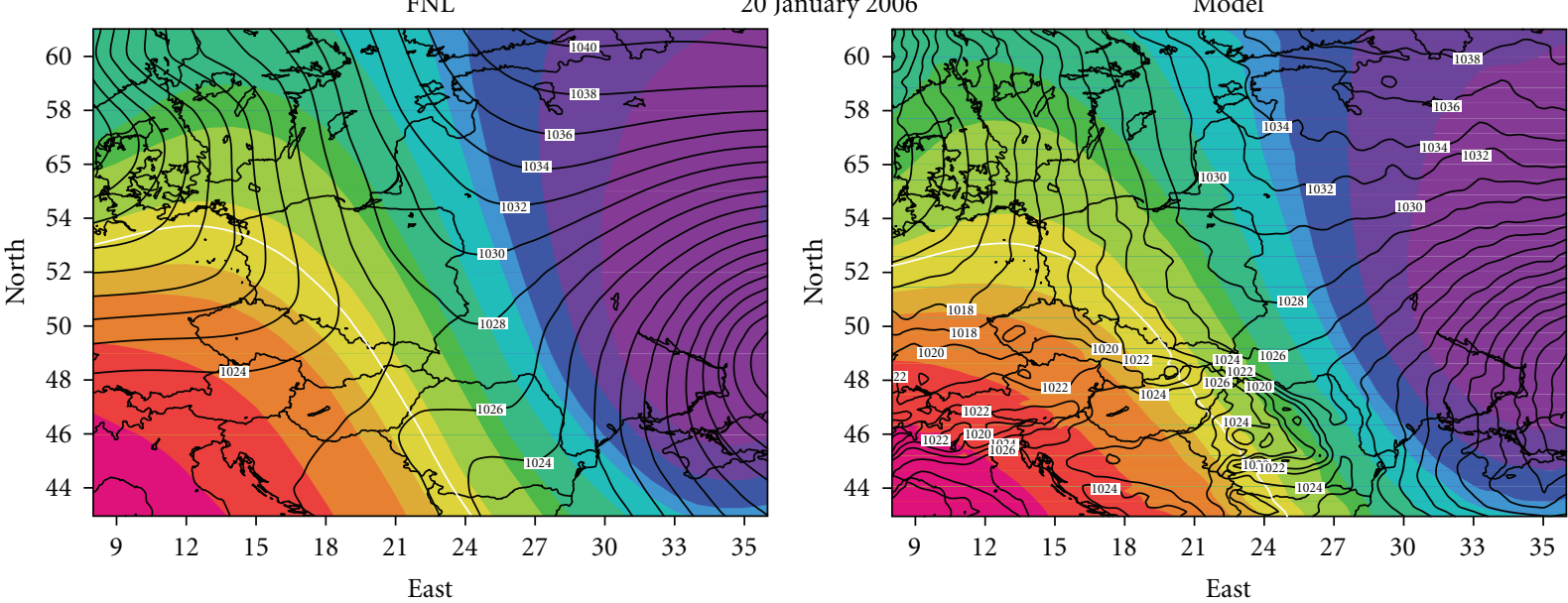

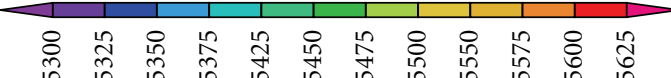

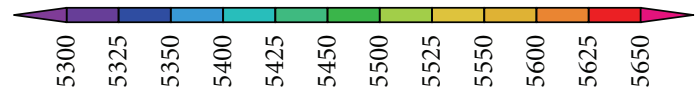

21 January 2006 Model
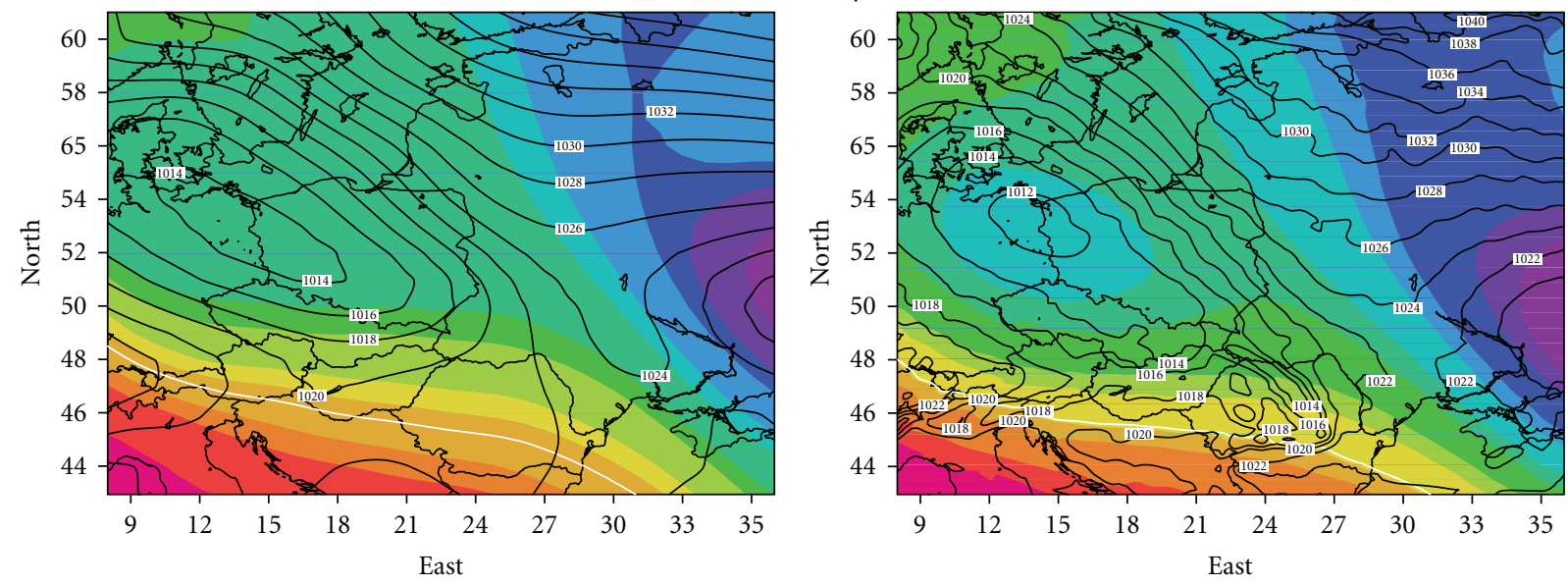

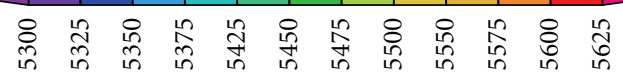

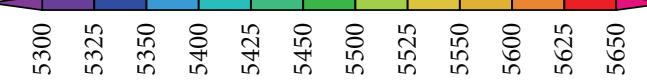

Figure 6: Continued. 


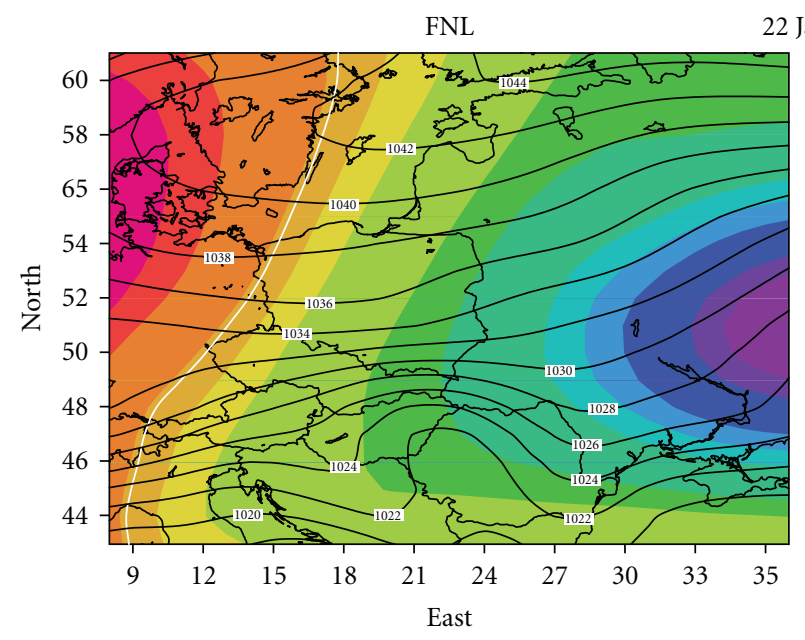

22 January 2006

Model
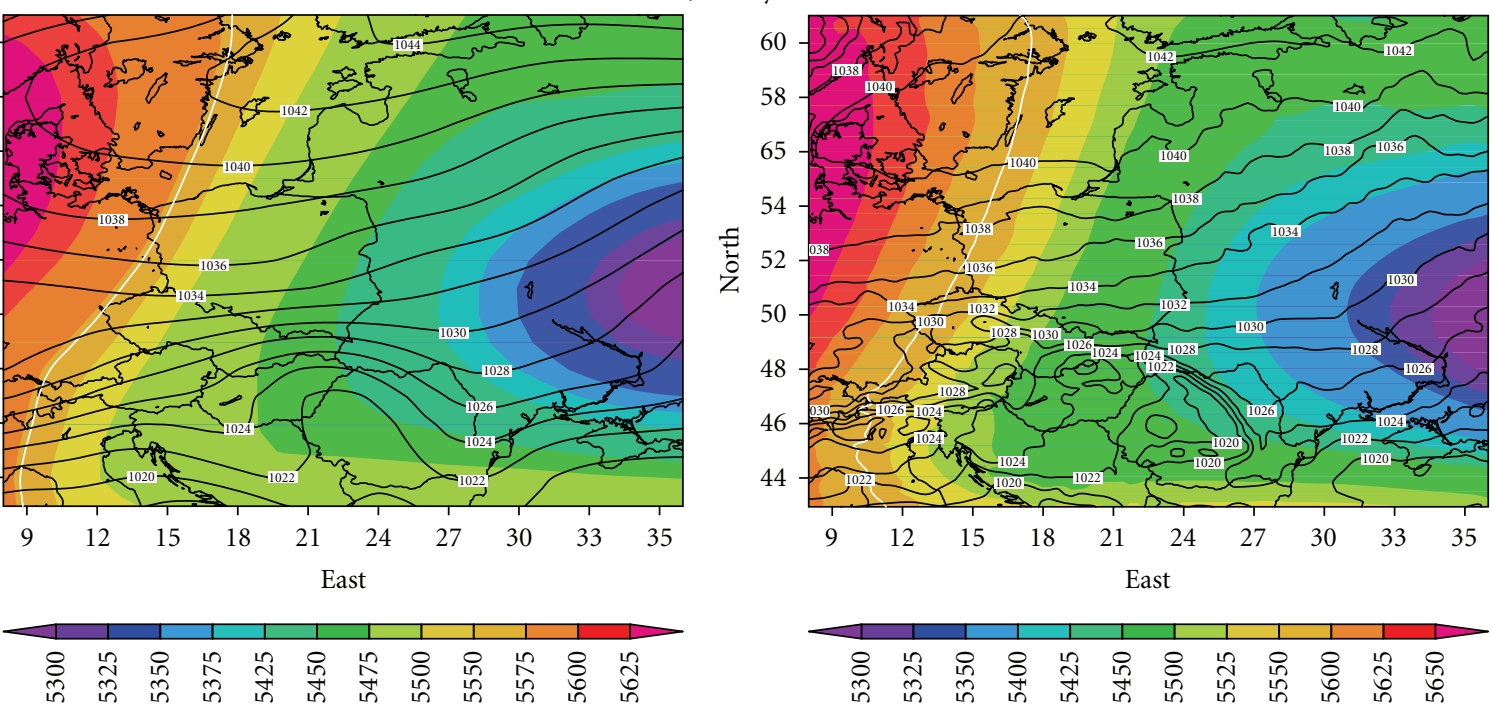

FNL

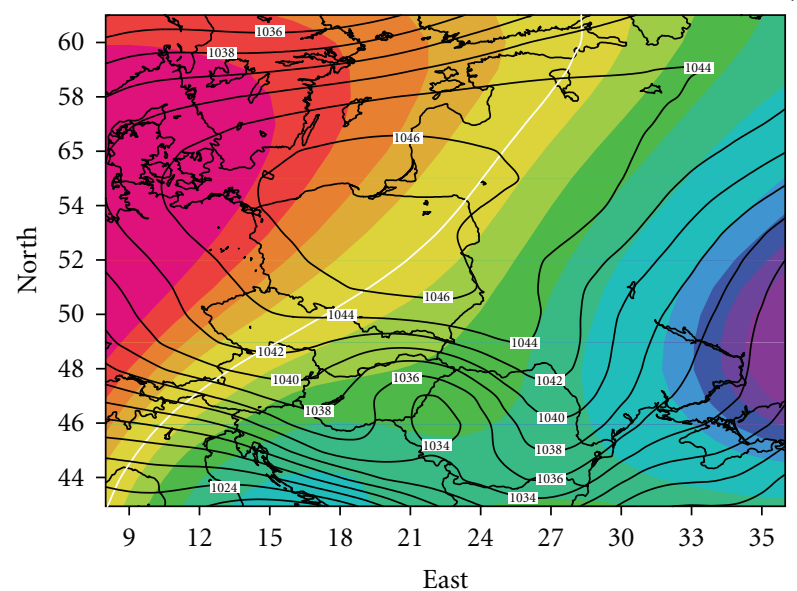

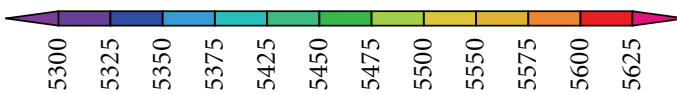

23 January 2006

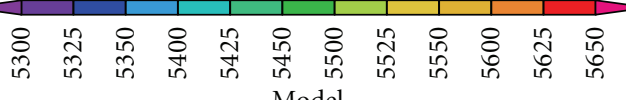

Model
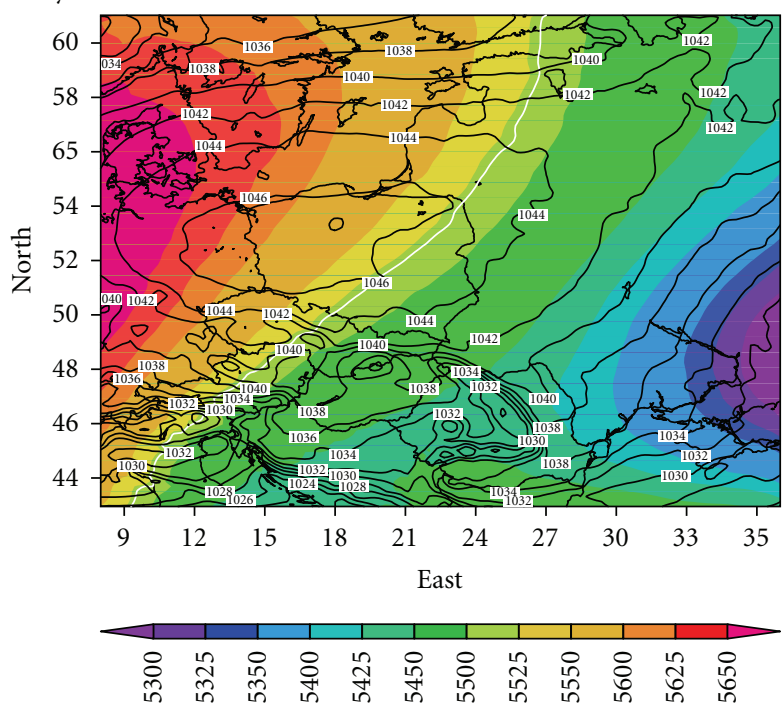

FIgURE 6: Daily mean geopotential height (gpm) at 500 hPa level (shaded) along with Surface pressure (hPa) (contours) for FNL (left panel) and ARW model (right panel) at different times.

intensity of the cold wave with a time lag of 1 to 3 days and its migration from north-eastern to the south-western parts of the domain. The model derived area averaged daily mean temperatures at $2 \mathrm{~m}$ height for different zones are found to match well with the averaged station daily mean temperature observations but with slight underestimation of about 5 to 10 degrees in temperature during the period of the intensive cold wave. A few exceptions are found for zones comprising ocean and adjoining land portions and for zones covering mountainous regions. Duration of the cold wave period is well agreeing with the observation but the model gets warmer one to two days before than the observations. Thus in general the ARW model seems to prove a useful modeling tool to simulate the seasonal climate with reasonable skill over extended range time scale and hence can be used to obtain an indication or a signal of the forthcoming extreme weather events such as cold wave conditions.
5.2. Model-Derived $2 \mathrm{~m}$ Air Temperature and Wind Flow at 925 $\mathrm{hPa}$. A detailed comparative analysis is made between FNL analysis data available at 1 degree resolution and model simulated products of the $2 \mathrm{~m}$ air temperature and winds at $925 \mathrm{hPa}$ level to assess how well the spatial trends of temperature and horizontal advective motion are simulated by ARW. The daily mean values for extreme cold days are computed for both temperature at $2 \mathrm{~m}$ and winds at $925 \mathrm{hPa}$ for both FNL and model outputs and presented in Figure 5. The spatial distribution of the wind flow on 19 January shows the presence of a strong cyclonic circulation over south-eastern parts of the domain in both model and FNL data and a strong easterly flow in the northern parts of the domain. These circulation features are well simulated by ARW model as seen from FNL data. The temperature pattern is almost the same in both model and FNL data except for the area under higher temperature contours relatively 
larger in the ARW simulation. This indicates that the model has produced a slightly warmer atmosphere than the FNL data. The FNL data indicated strong cold temperatures in the northeastern part which was not simulated by the model. The model showed a relatively warmer region in the northwestern part of the domain than the FNL data. On 20 January the cyclonic circulation has moved toward east, and an anticyclonic circulation is observed over north western parts of the domain in both model and FNL data. The simulated temperature pattern agrees with the FNL data but the area under higher temperature contours are relatively larger thus indicating a warm bias in model temperature. In the next 24 hours the cyclonic circulation has moved to west of Poland in both model and FNL. On 21 January the model temperatures are seen to be roughly 5 to $10^{\circ} \mathrm{C}$ lower over western part of the domain than the values from the FNL data. In all three days (19-21 Jan) westerly flow is noticed over western parts of the domain especially in the central and lower latitudes in both model and FNL data, and the wind is gradually intensified from 19 to 21 January. The simulated flow patterns are noted to agree well with the FNL but with little higher intensity. Also the fine-scale features are well resolved in the simulation which may be because of the model higher resolution than FNL. On 22 January the flow pattern was altered to easterly/northeasterly over much of the domain except for a small region in the northwestern portion where the flow had changed to southwesterly indicating the onset of an anticyclone. In the next day, that is, on 23 Jan the anticyclonic circulation was fully established over the whole Baltic Sea and neighborhood regions. These flow features are well simulated by the model. The simulated spatial temperature distribution also agreed well with FNL data but with a warm bias (about 5 to $10^{\circ} \mathrm{C}$ ) indicating less intensity of the simulated cold wave.

From the above discussions it is clear that the model could simulate most of the regional scale climate features comparable with FNL. The model is able to simulate the progression of the cyclonic and anti cyclonic circulations and trough and ridge regions with little higher intensity than those found in the FNL data. The model-derived temperature pattern agreed well with the FNL temperature distribution but with underestimation of cold conditions. The model simulated relatively higher temperatures at the colder region during extreme cold days and also relatively higher temperature in the warmer regions indicating a warm bias which needs to be examined further.

5.3. Model Derived Surface Pressure along with Geopotential at $500 \mathrm{hPa}$ Level. To understand the role of the pressure systems over the central Europe during the event of the extreme cold wave, the daily mean sea level pressure (SLP) along with the daily mean geopotential height at $500 \mathrm{hPa}$ level $(500 \mathrm{GH})$ is examined from the model and FNL data (Figure 6). The temporal sea level pressure and geopotential height patterns serve to describe the onset time and period of intensification of the cold wave between 18 to 24 January 2006.

On 18 of January 2006, a low-pressure system was located over the southwestern parts of Poland and the adjacent areas, and a high-pressure system (not shown) was located over the northeastern parts of the domain observed in FNL. This pattern was well simulated by the model, but with the low pressure system located over the Czech Republic and high pressure located over the northeastern parts of the domain. The high pressure system which caused the low temperatures over this area was evidently lower than the other parts of the domain. On the 19th of January, 2006 the low pressure system moved to the southeastern part of the domain in both FNL data and the simulation. Also, at the same time the high-pressure systems started moving towards the southwest portion of the domain. The thickness of the geopotential decreased over the entire region of the central Europe but was relatively higher over a small region of south western parts. These features would cause the air temperature over those areas to consistently decrease towards the minimum as seen from discussions in the previous sections. On 20 January, the low and high pressure systems sustained with small tilt towards the Southeast and Northwest, respectively, and a new low pressure system appeared over the northwestern part of the domain in both the model and the FNL. The geopotential height pattern indicates that the contours of higher geopotential height are concentrated over southwest part of the domain and all the other remaining area is with lower thickness. As the high-pressure system remained for a long duration over the central parts of Europe and north and northeastern parts of the domain, the air temperature in those areas dropped significantly. The temperature reached below $-20^{\circ} \mathrm{C}$ which was the monthly minimum in most of the central region. On the 21st of January 2008, the low pressure system from the northwestern part moved towards the South West and was located over the coastal parts of Denmark and the central part of Poland. At the same time, the high-pressure system was still dominating over the northeastern part of the domain. The thickness of the geopotential height further decreased over the entire region except the southern part of the domain. These features are well simulated by the model and agree well with FNL data. However, the intensity of the simulated low pressure system was slightly lower, and the location of the center of low pressure system was simulated over southern part of Poland and its adjacent parts. On 22 January, the low pressure system disappeared from the domain, and the highpressure system occupied the entire domain. On this day the geopotential pattern indicated higher thickness over northwestern part of the domain and lower thickness over remaining parts. Under this high pressure system the central part of the domain recorded very low temperatures which were simulated well by the model. On 23 January, a wellestablished high pressure system was located over the central part of the domain and remained over Poland for the next 48 hours. The geopotential pattern is almost similar to that of the previous day but with slightly higher thickness and a shift towards the east. Under this stable high pressure system especially over Poland the temperatures reached their monthly minimum values in those two days as low record. This prolonged cold wave situation could be simulated by the model. After 23 January the temperatures increased gradually in the northeastern part of the domain, and the 
TABLE 2: Number of the station observations considered for the average surrounded by the corresponding zones and the correlation coefficient values between the areas averaged daily mean temperatures at $2 \mathrm{~m}$ height from model and station observations.

\begin{tabular}{lcccccc}
\hline S. No & $\begin{array}{c}\text { Name of } \\
\text { the Zone }\end{array}$ & $\begin{array}{c}\text { Number of stations } \\
\text { (observations) considered } \\
\text { for comparison }\end{array}$ & BIAS & RMSE & $\begin{array}{c}\text { Standard } \\
\text { deviation }\end{array}$ & $\begin{array}{c}\text { Correlation } \\
\text { coefficient }\end{array}$ \\
\hline 1 & Zone 1 & 7 & 0.8105 & 4.543 & 7.7829 & 0.9439 \\
2 & Zone 2 & 6 & 0.4971 & 3.733 & 6.7153 & 0.9398 \\
3 & Zone 3 & 8 & -0.204 & 3.5012 & 6.3889 & 0.9530 \\
4 & Zone 4 & 7 & -0.236 & 4.0652 & 5.6857 & 0.8996 \\
5 & Zone 5 & 6 & 1.3872 & 3.1706 & 5.8532 & 0.9504 \\
6 & Zone 6 & 7 & 1.7921 & 4.3078 & 6.4188 & 0.8987 \\
7 & Zone 7 & 10 & 1.166 & 3.1988 & 4.2399 & 0.9303 \\
8 & Zone 8 & 11 & 0.8273 & 3.8727 & 5.1576 & 0.9004 \\
9 & Zone 9 & 5 & 2.4651 & 3.7733 & 4.2653 & 0.8835 \\
10 & Zone 10 & 8 & -1.621 & 2.5082 & 2.9767 & 0.7659 \\
11 & Zone 11 & 14 & 0.6357 & 1.8848 & 2.5269 & 0.7824 \\
12 & TOTAL & 89 & 0.6836 & 2.71 & 4.248 & 0.9447 \\
\hline
\end{tabular}

high pressure system disappeared slowly. By 25 January, 2006 the temperature increased and reached its normal value over entire Europe.

The model results suggest that it could simulate the passage of high and low pressure systems comparing closely with the trends from FNL data. The time series of simulated air temperature is found to match with the observed temperature time series in different zones. The model is able to resolve the regional scale features of the pressure systems which caused the spread of cold wave in the study domain.

\section{Summary and Conclusions}

A numerical modeling of extreme cold weather event over Europe during January 2006 was performed using the highresolution ARW model to examine the performance of the model for the seasonal climate simulation and to understand the probable causes of the cold wave formation.

The simulated daily mean $2 \mathrm{~m}$ air temperatures were analyzed and compared with the observed station surface temperatures. The model simulated winds at $925 \mathrm{hPa}, 2 \mathrm{~m}$ air temperatures, surface pressure, and geopotential height at $500 \mathrm{hPa}$ are compared with FNL data. Eight zones were identified on the basis of drop in mean daily temperatures below $-10^{\circ} \mathrm{C}$ and three zones based on the lowest temperatures above $-10^{\circ} \mathrm{C}$. The area averaged daily mean temperatures were computed from the model $2 \mathrm{~m}$ air temperature which were then compared with the averaged station surface temperatures from the respective zones.

The model-derived products showed a fall of temperatures starting from zone 1 located over northeastern parts to zone 11 located over the south western parts of the domain along with the passage of the high and low pressure systems in agreement with the station observations. The model is able to simulate the occurrence of the extreme cold situation at different zones and its temporal passage was reasonably well agreeing with observations but with lesser intensity. The model temperatures indicated a good correlation with observations above 0.76 at $95 \%$ significance. The simulated flow patterns during the passage of the cold wave are found to agree well with the FNL data which indicates that the model is able to capture the advection of cold temperatures associated with the high pressure systems. The lower atmospheric temperature could be simulated well by the model but with higher temperatures than observed. The model results show warmer bias in extreme cold days. The persistent cold condition spanning 3 to 5 days over different zones could be captured by the model. This cold condition is known from its impact on economy and the death rate, especially in Russia, Ukraine, Poland, and some parts of the adjacent regions.

The present study attempted to simulate one extreme cold event due to the availability of limited computational resources. In order to assess the skill of the model for extended range seasonal climate forecasting it would be desirable to examine the model performance for a series of events over past few years. However, the results from the present study provide an indication of skill of the ARW model for its application for the extended range weather forecasting for Central Europe region during the winter season which may help to give an indication of the extreme events like cold waves for use by the public as well as the policy makers to take disaster mitigation measures. In the present study the ARW model is run with the initial and boundary conditions adopted from the NNRP data. In order to use the ARW model for near-real time applications of regional climate forecasting it would be necessary to run the model with a global domain initialized once with either GFS or other global analyses and thus provides the time-varying lateral boundary conditions from the global domain to a regional domain for region-specific climate forecasting, which would be tested in the future studies. 


\section{Application of Dynamical Models in Disaster Mitigation}

The ARW model (as well as other dynamical mesoscale models) has been routinely applied for weather forecasting and as a part of a disaster mitigation tool in many countries. In this present study, the ARW model was used to study the regional climate feature over Central Europe with $30 \mathrm{~km}$ resolution during the period from 1st to 31 st January 2006. The real-time integrations require large scale lateral boundary conditions and initial conditions that are now available in a near-real time basis from global operational forecast centers over different parts of the globe. The global products are available at a coarse resolution of 150 to $300 \mathrm{~km}$. High-resolution mesoscale models are required to study and understand the intensity and its passage or movement of the extreme events like cold waves, heat waves, and flash floods and so forth, which are orographically and convectively driven. Mesoscale models with regional analysis and better representation of the initial conditions and local forcing have to be adopted when applying for specific regions.

The regional climate models are useful to give a better forecast for planners in advance to implement disaster mitigation measures over particular regions in such aspects as agricultural operations, food storage, and energy storage, to improve public transportation facilities and so forth, which may be useful to save large economy and death rates, especially during cold and heat wave conditions.

\section{Acknowledgments}

This paper was supported by an STATME project within the 6th European Community Framework Programme through contract MTKD-CT-2004-014222 and the Polish Ministry of Science and Higher Education under Grant K 091/Po4/2004/11. The data for this study are from the Research Data Archive (RDA) which is maintained by the Computational and Information Systems Laboratory (CISL) at the National Center for Atmospheric Research (NCAR). NCAR is sponsored by the National Science Foundation (NSF). The original data are available from the RDA (http://dss.ucar.edu/) in dataset number ds090.0

\section{References}

[1] A. M. G. Klein Tank and G. P. Können, "Trends in indices of daily temperature and precipitation extremes in Europe, 1946-99," Journal of Climate, vol. 16, no. 22, pp. 3665-3680, 2003.

[2] A. Moberg and P. D. Jones, "Trends in indices for extremes in daily temperature and precipitation in central and western Europe, 1901-99," International Journal of Climatology, vol. 25, no. 9, pp. 1149-1171, 2005.

[3] R. Heino, R. Brázdil, E. Førland et al., "Progress in the study of climatic extremes in Northern and Central Europe," Climatic Change, vol. 42, no. 1, pp. 151-181, 1999.

[4] J. Wibig and B. Glowicki, "Trends of minimum and maximum temperature in Poland," Climate Research, vol. 20, no. 2, pp. 123-133, 2002.
[5] The BACC Author Team, Assessment of Climate Change for the Baltic Sea Basin, Springer, Berlin, Germany, 2008.

[6] M. M. Huynen, P. Martens, D. Schram, M. P. Weijenberg, and A. E. Kunst, "The impact of heat waves and cold spells on mortality rates in the Dutch population," Environmental Health Perspectives, vol. 109, no. 5, pp. 463-470, 2001.

[7] J. E. Walsh, A. S. Phillips, D. H. Portis, and W. L. Chapman, "Extreme cold outbreaks in the United States and Europe, 1948-99," Journal of Climate, vol. 14, no. 12, pp. 2642-2658, 2001.

[8] J. S. Kain and J. M. Fritsch, "Convective parameterization for mesoscale models: the Kain-Fritsch scheme," in The Representation of Cumulus Convection in Numerical Models, K. A. Emanuel and D. J. Raymond, Eds., Amer. Meteor. Soc., 1993.

[9] J. S. Kain and J. Kain, "The Kain-Fritsch convective parameterization: an update," Journal of Applied Meteorology, vol. 43, no. 1, pp. 170-181, 2004.

[10] R. E. Dickinson, R. M. Errico, F. Giorgi, and G. T. Bates, "A regional climate model for the western United States," Climatic Change, vol. 15, no. 3, pp. 383-422, 1989.

[11] F. Giorgi and G. T. Bates, "The climatological skill of a regional model over complex terrain," Monthly Weather Review, vol. 117, no. 11, pp. 2325-2347, 1989.

[12] F. Giorgi, C. Shields Brodeur, and G.T. Bates, "Regional climate change scenarios over the United States produced with a nested regional climate model," Journal of Climate, vol. 7, no. 3, pp. 375-399, 1994.

[13] H. Hirakuchi and F. Giorgi, "Multiyear present-day and $2 \times \mathrm{CO} 2$ simulations on monsoon climate over eastern Asia and Japan with a regional climate model nested in a general circulation model," Journal of Geophysical Research, vol. 100, no. D10, pp. 21,105-21,125, 1995.

[14] R. G. Jones, J. M. Murphy, and M. Noguer, "Simulation of climate change over Europe using a nested regional-climate model. I: assessment of control climate, including sensitivity to location of lateral boundaries," Quarterly Journal of the Royal Meteorological Society, vol. 121, no. 526, pp. 1413-1449, 1995.

[15] R. G. Jones, J. M. Murphy, M. Noguer, and A. B. Keen, "Simulation of climate change over Europe using a nested regionalclimate model. II: comparison of driving and regional model responses to a doubling of carbon dioxide," Quarterly Journal of the Royal Meteorological Society, vol. 123, no. 538, pp. 265292, 1997.

[16] J. H. Christensen, B. Machenhauer, R. G. Jones et al., "Validation of present-day regional climate simulations over Europe. LAM simulations with observed boundary conditions," Climate Dynamics, vol. 13, no. 7-8, pp. 489-506, 1997.

[17] F. Georgi and L. O. Mearns, "Regional climate modeling revisited: an introduction to the special issue," vol. IC/98/191, 1-44, 1998, http://www.ictp.trieste.it/ pub_off.

[18] W. Wang, D. Barker, C. Bruyère, J. Dudhia, D. Gill, and J. Michalakes, "WRF Version 2 modeling system user's guide," 2004, http://www.mmm.ucar.edu/wrf/users/docs/user_guide/.

[19] J. Michalakes, J. Dudhia, D. Gill, et al., "The weather research and forecast model: software architecture and performance," in Proceeding of the 11th ECMWF Workshop on the Use of High Performance Computing in Meteorology, G. Mozdzynski, Ed., Reading, UK, October 2004.

[20] W. C. Skamarock, J. B. Klemp, J. Dudhia, et al., "A description of the Advanced Research WRF Version 3," Technical Note TN-475+STR, NCAR, 2008. 
[21] E. Kalnay, M. Kanamitsu, R. Kistler et al., "The NCEP/NCAR 40-year reanalysis project," Bulletin of the American Meteorological Society, vol. 77, no. 3, pp. 437-471, 1996.

[22] A. M. G. Klein Tank, J. B. Wijngaard, G. P. Können et al., "Daily dataset of 20th-century surface air temperature and precipitation series for the European Climate Assessment," International Journal of Climatology, vol. 22, no. 12, pp. 14411453, 2002. 

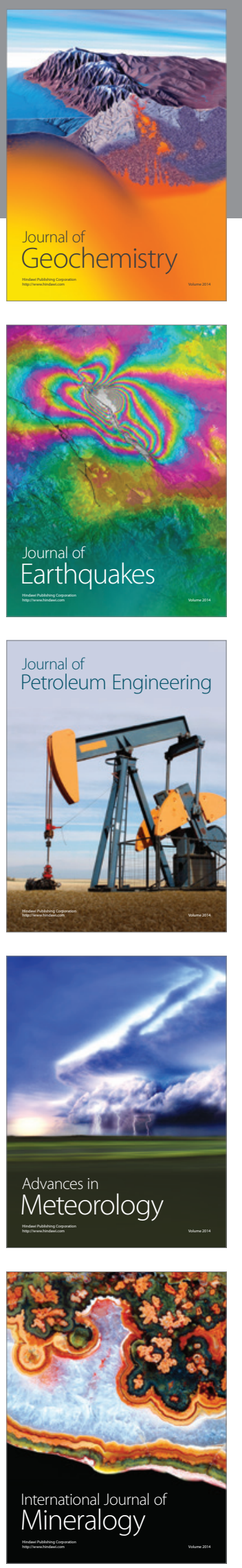
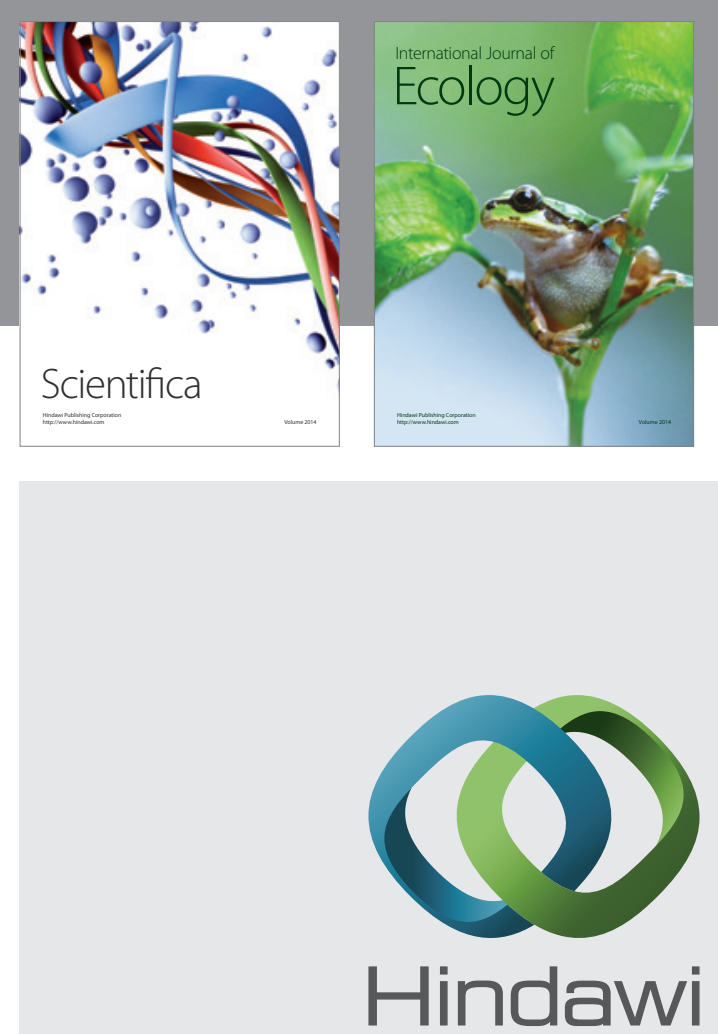

Submit your manuscripts at http://www.hindawi.com
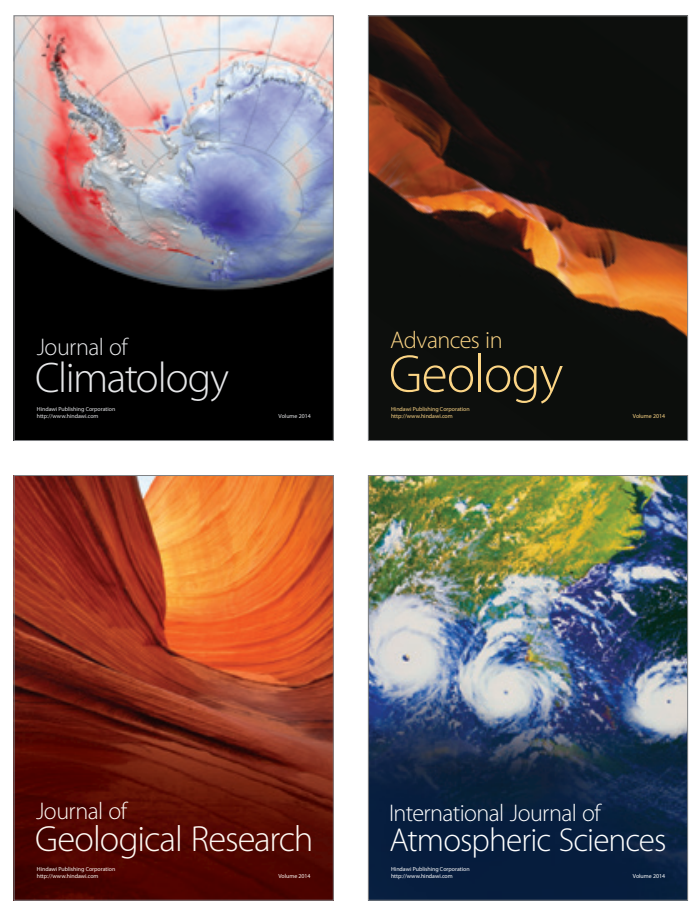
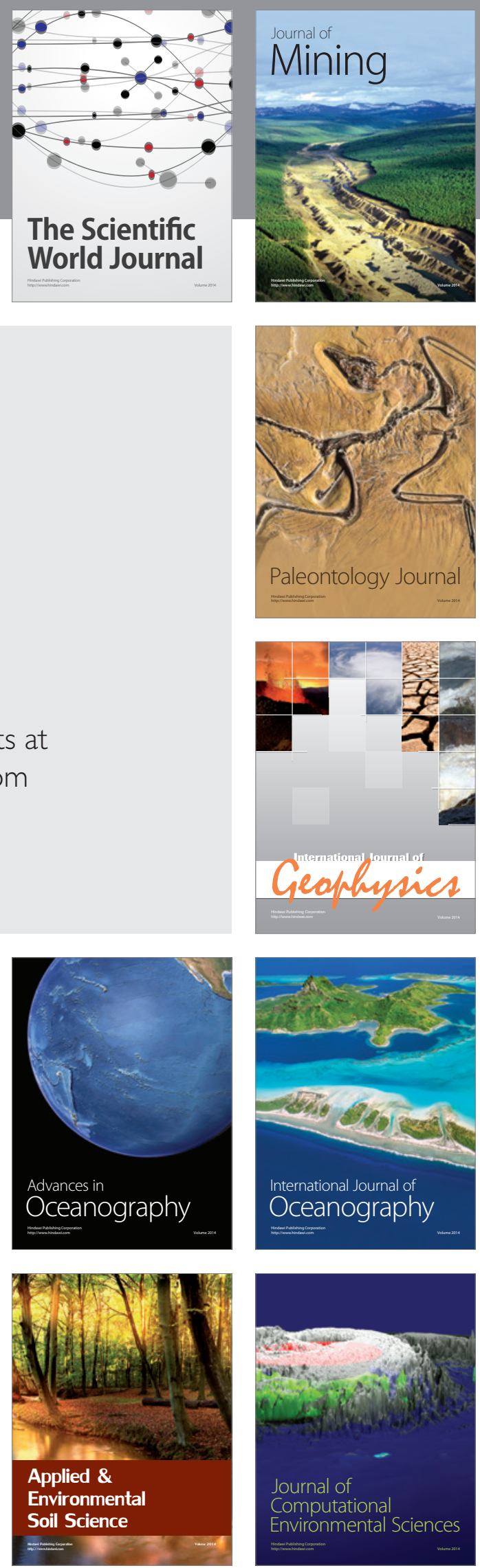